\title{
¿Cómo funcionan las organizaciones del Tercer Sector? Análisis de la estructura y de las dinámicas organizativas
}

\section{Manuel Herrera Gómez *}

\section{Introducción}

Actualmente se encuentra muy difundida la siguiente convicción: en las sociedades contemporáneas, tanto en las llamadas en "vias de desarrollo como en las "avanzadas", el Tercer Sector ${ }^{1}$ es un fenómeno emergente. Su importancia está en aumento. Buena muestra de ello nos la ofrece su creciente intervención en un amplio número de campos y actividades humanas: desde los servicios educativos y de formación, a los sanitarios y sociales, desde las actividades deportivas y de tiempo libre, a las artísticas y científicas, desde el campo de la protección civil, al terreno ecológico y de relación con la naturaleza física y medio-ambiental, desde la defensa de los consumidores, a la protección humana, desde la ayuda a personas con dificultades, a la re-integración social de las capas más débiles y marginadas de la población. Conviene subrayar que no sólo se trata de situaciones, condiciones y contextos de carácter patológico. También son de carácter normal, es decir, de vida cotidiana de una comunidad en el sentido más amplio y ordinario del término. En breve, estamos ante una verdadera y propia explosión de las formaciones sociales que se agrupan bajo la etiqueta del :Tercer Sector.

Las formas que tales expresiones organizadas de la sociedad civil pueden asumir son múltiples (fundaciones, asociaciones, entes para-estatales o semi-públicos, organizaciones sin fines de lucro, organizaciones de voluntariado, cooperativas sociales, grupos de mutua y auto-ayuda, ...) y hacen referencia a una pluralidad de modelos administrativos y de gestión mayor que la que podemos encontrar en el sector público o en el merca- do. La amplitud de sectores y ámbitos de intervención anteriormente apuntados añaden complejidad al cuadro de referencia, alimentando la imagen de un sector económico-social fragmentado o débilmente consistente.

Ante esta riqueza, en términos de formas institucionales y soluciones organizativas, hay que señalar la notable carencia de reflexiones teóricas y estudios empíricos que tengan en cuenta la peculiaridad de este sector ${ }^{2}$. Dicha carencia especialmente se manifiesta en lo referente al desarrollo de técnicas manageriales y modelos organizativos adecuados. Dicho de otra manera, existe una amplia laguna en torno a temas fundamentales como: el funcionamiento de las organizaciones del Tercer Sector, las caracteristicas estructurales que presentan y cuáles son sus principales dinámicas organizativas. Utilizando el lenguaje de un interesante planteamiento de la teoría de las organizaciones ${ }^{3}$, bien poco se conoce sobre cómo nacen, crecen, se desarrollan, cambian y, eventualmente mueren, los miembros de este amplio universo de las poblaciones organizativas.

$\mathrm{Si}$ éstos son los rasgos que caracterizan el panorama internacional, la situación en nuestro país presenta matices más negativos. Mientras que en los países anglosajones es posible encontrar cursos de formación, escuelas de post-grado, programas master expresamente dedicados a la enseñanza de técnicas de gestión aplicadas al campo de las organizaciones sin fines de lucro ${ }^{4}$, en España no ocurre lo mismo.

A pesar de esto, detrás de situaciones como el recorte del gasto público o el crecimiento progresivo de las dimensiones organizativas de los sujetos sin fines de lucro, crece (también en España y por parte de dirigentes, operadores, voluntarios-0. 
simples financiadores del sector) la demanda de conocimiento de los instrumentos operativos y de gestión con los que conducir de forma racional este tipo de organizaciones. A esta demanda cognoscitivo-formativa no sólo se vinculan razones de mejora del funcionamiento y de las prestaciones organizativas (eficacia y eficiencia), también hace acto de presencia una clara conciencia en torno a la necesidad de adquirir una mayor autonomía financiera y de gestión.

En estas páginas se pretende elaborar un primer cuadro sobre los problemas organizativos y de gestión propios de las organizaciones sin fines de lucro. Se intenta abrir un debate, lanzar un desafío que, espero, venga recogido tanto por los operadores (dirigentes, personal, contratado, voluntarios), como por los estudiosos que se acercan a lo que ARDIGo llama el gran desconocido de las formaciones sociales. ${ }^{5}$.

Para cumplir este objetivo, en primer lugar es necesario afrontar las peculiaridades que configuran las organizaciones del Tercer Sector como una tipología organizativa sui generis. Ésta es la finalidad del primer apartado. En él se intentan establecer las características estructurales que diferencian a estas organizaciones de las agencias públicas y de las empresas de mercado, en términos de praxis operativas y modalidades de gestión.

Establecido este punto de partida podrán abordarse temas como el management de las organizaciones de Tercer Sector, el gobierno y la gestión de la organización, la planificación organizativa y la gestión del cambio y los criterios que definen el "éxito para este tipo de organizaciones.

\section{2. ¿En qué son diferentes las organizaciones del Tercer Sector? El carácter específico del non profit}

En primera instancia, el Tercer Sector puede ser definido como aquel complejo de organizaciones que están caracterizadas por:

1. Una cultura que empuja a los singulares individuos, singulares familias y singulares grupos sociales a relacionarse de manera solidaria con otros (extranjeros, no familiares, ...). En concreto, para quien realiza acciones del Tercer Sector, vienen excluidas motivaciones y finalidades puramente económicas (de lucro, beneficio, ventajas materiales o monetarias, fringe benefits, ...). Esto puede ser garantizado siempre que en el estatuto o acto constitutivo de la organización esté prevista la no distribución de beneficios (non distribution constraint). Ahora bien, conviene senalar que se trata de un criterio necesario, pero no suficiente.

2. Una autorregulación de los actores que se inspira en normas que van desde el puro don al intercambio de reciprocidad (pero siempre sin el fin de las ventajas económicas).

3. Una organización operativa que debe poseer un mínimo de criterios de gestión formalizada, hecho éste que corresponde a ciertos requisitos de transparencia y claridad pública con algunos instrumentos de equilibrio social.

4. Un específico rol societario centrado en la producción de bienes relacionales colectivos ${ }^{6}$, con relaciones privilegiadas de ósmosis con el cuarto sector (familia y redes informales) y un mix de diversa naturaleza por cuanto concierne a los input-ouput con los otros sectores (Estado y Mercado).

Esta primera aproximación, resultado de la observación externa e interna ${ }^{7}$ del Tercer Sector, puede declinarse a través de una serie de posteriores connotaciones específicas que se sintetizan así:

- Las organizaciones del Tercer Sector tienen una precisa formalización juridica que será, en general, un compromiso entre la propia naturaleza (mission) y las formas institucionales disponibles (para los países del civil law, aquellas que los códigos civiles y las diversas leyes ordinarias establecen, siendo el Estado el que forja el sujeto de Tercer Sector en cuanto que le obliga a cumplir una serie de requisitos si quiere. ser reconocido y entrar en relación con otras instituciones).

- Las organizaciones del Tercer Sector son autónomas bajo el perfil organizativo y de gestión. Dicho de otra manera, presentan una operatividad propia caracterizada por el hecho de movilizar particulares recursos y combinarlos según sus propias modalidades.

- Estas organizaciones deben someterse al non distribution constraint, no distribuyendo los eventuales y posibles beneficios entre los accionistas.

- La acción desarrollada debe tener un interés público.

A pesar de las diversas posiciones, y de los distintos planteamientos teóricos y empíricos en torno al Tercer Sector y sus organizaciones, emerge un sustancial acuerdo, un mínimo común denominador entre los estudiosos del management y los managers del sector al definir sus organizaciones: el núcleo central de estas organizaciones viene identificado en la :non distribution constraint. Es decir, nos encontramos ante un tipo de organizaciones cuyo objetivo es totalmente diverso del producir 
un beneficio (ganancia, provecho, útil) para los propietarios; en general, el fin último es proporcionar servicios. Sobre este cometido, HANSMANN señala que e una organización non-profit es en sustancia una onganización sujeta a la probibición de distribuir sus beneficios netos, aunque éstos existan, a todos aquellos que realizan sobre ella un control, por ejemplo, miembros, funcionarios, dirigentes $y$ administradores ${ }^{8}$.

Identificado uno de los ejes centrales de este tipo de organizaciones, a partir de él se deriva una de las características fundamentales que las diferencia de las empresas de mercado: $s i$ en estas últimas el objetivo de los dirigentes es la maximización del beneficio, en las organizaciones del Tercer Sector las decisiones tomadas por el manager están encaminadas a asegurar la elaboración del mejor de los servicios posibles en función de los recursos disponibles. Por tanto, si para las empresas de mercado el éxito viene dado por el incremento de los beneficios, en las organizaciones del Tercer Sector el éxito fundamentalmente se mide en función de la cantidad de servicios que la organización produce y el modo en que estos servicios son distribuidos. En general, el éxito de una organización de Tercer Sector debe ser valorado en la medida en que contribuye al bienestar priblico en términos de eficacia social más que de achivement instrumental ${ }^{9}$.

La presencia de estas dos connotaciones, eficiencia en términos de calculabilidad social más que de calculabilidad económica y éxito en términos de reficacia social más que de achivement instrumental, obligan a los sujetos de Tercer Sector a expresar formas organizativas y operativas específicas en las que poder realizar la propia misión (mission, como dicen los anglosajones).

Sobre este punto la claridad aún es mínima. La mayor parte de los estudios organizativos desarrollan sus análisis aplicando al Tercer Sector los esquemas de empresas de mercado o los esquemas de organizaciones burocráticas públicas, procediendo posteriormente mediante deducciones comparativas. Un buen ejemplo de esto lo encontramos en el uso analógico que se hace del concepto de redes. Éste es utilizado indiferentemente para el estudio del mercado, de los servicios públicos, así como para las organizaciones del Tercer Sector. Personalmente creo que el concepto de redes necesita de una formulación cualitativamente adecuada al sector en que viene aplicado. La red de las burocracias es formal-legal, estando orientada a la ejecución de objetivos y tareas. La red de las empresas de mercado es productivo-informativa, dirigiéndose a la maximización de la eficiencia. La red de de las organizaciones del Tercer Sector no puede ser ni del tipo formal-legal (burocracias públicas), ni del tipo productivo-informativa (empresas de mercado). En concreto, debe activar el sentido de la intercambiabilidad social propia de un campo de actividad que, por fuerza de los acontecimientos, tiene que interseccionar informal y formal, dando prioridad a la primera y, cientamente, no con vistas a la maximización de la eficiencia.

Tomando como punto de partida las premisas anteriormente expuestas, una serie de estudios e investigaciones han tratado de poner luz a las características del proceso productivo y de los sistemas de control de la gestión utilizados por las organizaciones del Tercer Sector. El fin no era otro que hacer evidentes los puntos de fuerza y de debilidad de este tipo de organizaciones.

Hay quien ha intentado individuar las peculiaridades de este universo organizativo, peculiaridades que dejarían sentir su influencia en el proceso de control de la gestión ${ }^{10}$. Éstas pueden quedar sintetizadas en el siguiente elenco:

- ausencia de una medida de beneficio;

- diverso statús legal y fiscal;

- tendencia a ser organizaciones que producen servicios;

- mayores límites en los objetivos y en las estrategias;

- menor dépendencia de la clientela para el apoyo financiero;

- dominio de profesionales (médicos, abogados, enfermeros, asistentes sociales);

- diferencias en el modo de gobiemo;

- diferencias en el management;

- peculiar importancia de la influencia política;

- persistencia de un uso inadecuado de los sistemas de control de la gestión.

Este conjunto de peculiaridades se agruparían así:

a) Las características técnicas.

b) Las caracteristicas operativas o comportamentales.

El primer grupo comprende aquellas cuestiones referentes a la ausencia del beneficio como medida de las prestaciones realizadas por la organización. El segundo agrupa todos los otros aspectos. La principal condusión que se puede extraer es la siguiente: la no existencia de una singular, suficiente, y general medida de las prestaciones que sea comparable al criterio del beneficio de las empresas de mercado (es decir, la dificultad de medir los output $y$ la relación entre input $y$ output), constituye un fuerte obstáculo que impide el desarrollo de eficaces sistemas de control de la gestión en las organizaciones del Tercer Sector.

En cuanto unidad de medida, el beneficio permite las siguientes prestaciones:

1. Elaborar un criterio: singular que puede ser usado para valorar cursos de acción alternativa. 
2. Realizar un análisis cuantitativo de estas alternativas a partir del cual los beneficios pueden ser directamente comparados con los costes.

3. Forjar una única y amplia medida de las prestaciones.

4. Permitir la descentralización de las funciones de dirección y de gestión.

5: Facilitar la comparación de la prestación entre unidades que desarrollan funciones diversas.

Aun siendo interesantes cada una de estas aportaciones, nos encontramos ante algunas de las deficiencias que anteriormente anunciábamos: la aplicación al Tercer Sector y sus organizaciones de los esquemas pertenecientes a las empresas de mercado. Considerar la ausencia de beneficios, al estilo de las empresas de mercado, como el gran obstáculo que impide el desarrollo de eficientes sistemas de control de la gestión en este tipo de organizaciones significa no haber comprendido:

A. Los contextos socio-económicos en los que se desarrollan las organizaciones del Tercer Sector. Es alli donde el Mercado y el Estado se encuentran relativamente desarrollados y diferenciados donde emergen exigencias referentes a otras formaciones sociales que corresponden a otras dimensiones relacionales (no estatales y no de beneficio).

B. Los procesos que dan vida al Tercer Sector y sus organizaciones. Son las mismas redes sociales que, después de haberse diferenciado, deben producir esferas de relaciones cuya especialización estructural, cultural y organizativa consiste en integrar (o al menos relacionar de manera solidaria) aquello que ha estado diferenciado. En consecuencia, los procesos que originan el Tercer Sector son procesos de diferenciación reticular, en cuanto que representan la creación de redes más complejas que aquellas que daban orden a la sociedad precedente: por una parte, las redes del Tercer Sector son más flexibles, móviles y contingentes, por otra, son capaces de dotarse de nuevas formas de relación que son propiamente las organizaciones del Tercer Sector.

Teniendo presente los contextos (desarrollados y diferenciados) y los procesos (de diferenciación reticular), se comprende por qué el Tercer Sector y sus organizaciones no tienen, ni pueden tener, el carácter de una gestión económicamente inspirada en el máximo de utilidad, comparable a la gestión de las empresas de mercado que tienen como propium el primado funcional del dinero. La ausencia de beneficios como unidad de medida de las prestaciones no es que sea el obstáculo que impide a este tipo de organizaciones desarrollar eficaces sistemas de control de la gestión. El problema es otro y, en consecuencia, debe enfocarse desde otra perspectiva, teniendo presente que el Tercer Sector y sus organizaciones constituyen un fenómeno social emergente en sentido específicamente sociológico ${ }^{11}$.

Si se tiene presente que el primer y principal criterio de operatividad para el Tercer Sector y sus organizaciones está constituido por el continuum informal-formal, entonces el problema de fondo -y lo paradójico- de este tipo de organizaciones consiste en que: para alcanzar los propios objetivos debe adoptar grados más elevados de formalización, pero, cuanto más se formaliza, más se aleja de aquellas connotaciones relacionales que aseguraban el espiritu, la mission, las motivaciones, en fin, el empuje del mundo vital. En cierto sentido, la optimización operativa no consiste en ser más rentable, más bien en encontrar un propio punto de equilibrio dinámico, procesual, entre resultados y recursos humanos, teniendo en cuenta que, por un lado, un exceso de informalidad comporta una renuncia o la falta de una adecuada profesionalidad (o bien de mentalidad profesional o tecnológica) y, por otro, un exceso de formalización conlleva el ingreso en lógicas de rigidez y de despersonalización que producen déficits motivacionales y de sentido en los miembros.

Algunas investigaciones han individuado en la categoria del -ser pública (publicness = grado de publicidad) el trato distintivo de estas organizaciones respecto a las del mercado ${ }^{12}$. Hechos tales como el estar sujetas a influencias y controles por parte de la autoridad pública, el elevado grado de visibilidad pública de las operaciones, el tener que dar cuenta en última instancia a la comunidad en que actúan, hacen que las organizaciones del Tercer Sector sean comportamientos organizativos sui generis (con un nivel de publicness ubicado entre el máximo del Estado y el mínimo de las empresas con fines de lucro). Esto se refleja de manera significativa en los procesos organizativos y, por tanto, en los instrumentos de gestión utilizados.

Efectivamente, las organizaciones del Tercer Sector son organizaciones sui generis. Ahora bien, utilizando la categoría sser puiblico se corre el riesgo de presentar a estas organizaciones como una combinación o mediación entre dos polos: el polo público y el polo privado. De aquí se deriva la posibilidad de establecer unos parámetros faltos de dinamicidad para valorar la verdadera naturaleza organizativa de estas organizaciones y sus correspondientes repercusiones en los procesos organizativos y en los instrumentos de gestión utilizados. En breve, la individuación de la categoría ser puiblico coloca a las organizaciones del Tercer Sector en el centro de un continuum oscilatorio que no permite ligar las líneas de fuerza (distinciones-guia) intemas a los diversos sectores, a sus combinaciones e interacciones. En la actualidad, definir el Tercer Sector a partir de la distinción puiblico-privado es demasiado simple, no teniendo presente dicha distinción la complejidad de los fenómenos en acto. En mi opinión, el Tercer Sector y sus organizaciones no son un mix de público y privado, sino realidades sui generis constituidas de 
propias esferas que se encuentran en relaciones sistémicas con los otros tres sectores (Estado, Mercado y Redes Primarias). Más concretamente, la organización operativa de las organizaciones del Tercer Sector debe observarse como un sistema de relaciones, internas y externas, con los otros tres sectores, tomando como piedra angular no las empresas de mercado o los servicios estatales, sino haciendo referencia a las organizaciones de los grupos secundarios.

Aquellos análisis que se han centrado en el estudio de organizaciones religiosas subrayan como característica fundamental de las organizaciones del Tercer Sector el hecho de ser organizaciones expresivas de valores ${ }^{13}$. Ello implica que su modo de actuar y el tipo de relaciones que establecen constituyen un elemento derivado de los valores que tales organizaciones representan. En consecuencia, surge el problema de cómo es posible definir y valorar la eficacia de organizaciones que son, al mismo tiempo, instrumentos de testimonio y agencias distribuidoras de servicios. Estos factores dejan sentir su influencia tanto en la modalidad de realización de las campañas de recogida de fondos (el mensaje que se transmite debe ser verdadero y veraz), como en la gestión de los recursos humanos (todos los miembros de la organización, independientemente del rol desempeñado, deben ser tratados según una determinada concepción de las relaciones personales y una atención por el desarrollo de la persona).

Presentar las organizaciones del Tercer Sector como organizaciones expresivas de valores significa revelar uno de los ejes centrales del Tercer Sector: la presencia de una propia cultura. Este elemento debe ser afrontado y definido antes de analizar sus posibles repercusiones en la actuación de las organizaciones del Tercer Sector. De no hacerlo se corre el riesgo de identificar tout court el Tercer Sector y sus organizaciones con islas de marginalidad como pueden ser las acciones de compasión, beneficencia, de asistencia al necesitado. Aún más, quien exalta la naturaleza desinteresada, de puro don y de total gratuidad de estas modalidades organizativas, olvida que:

1. El Tercer Sector y sus organizaciones constituyen un campo de actividades que sirven para entrar en el mundo profesional.

2. Las organizaciones del Tercer Sector tienen necesidad de una cierta calculabilidad (tanto más en cuanto que usan el dinero y otros medios propios del mercado).

3. Tienen necesidad de adecuarse a ciertas normas legislativas (condiciones puestas por el Estado).

Las motivaciones y los valores culturales del Tercer Sector y sus organizaciones generalmente son aquellos de ir al encuentro de las necesidades del otro mediante ayudas que sean concretas y, lo más posible, relacionadas inter-subjetivảmente. Altruismo, don, solidaridad, confianza, reciprocidad, son - por lo gene- ral- las motivaciones y los valores en los que se inspira la acción de las organizaciones del Tercer Sector ${ }^{14}$. Sin embargo, la cultura -motivaciones y valores - propia de estas organizaciones también puede ser leída e interpretada como exigencia de encontrar nuevas formas de mix entre Gemeinschaff y Gesellchaff ${ }^{15}$ Aquí encontramos el carácter relacional (reticular) de la identidad y de los intereses de los nuevos sujetos sociales de los que nos ocupamos. Se trata de identidades que se forman en estrecha interacción con intereses que no pueden ser definidos solamente en sentido instrumental y que, por otro lado, no pueden ser considerados a priori como gratuitos o de puro y simple altruismo. La cultura de las organizaciones del Tercer Sector, por una parte, amplía interiormente las relaciones que están entre el beneficio y el no beneficio, entre la intersubjetividad de los ciudadanos y las acciones del Estado, por otra, aspira a combinar ciertas motivaciones ideales con formas eficaces de intervención dotadas de estabilidad, respondiendo, por su propia relacionalidad, a necesidades sociales no ocasionales, sino más bien profundamente insertadas en el tejido social.

Tras haber analizado la función de gobierno de las organizaciones del Tercer Sector, M. MIDDLETON individúa tres características base de estas organizaciones que influencian de manera decisiva el actuar de los consejos de administración (comités de gestión):

a) Sus objetivos son vagos, ambiguos, de difícil cuantificación y abiertos a una pluralidad de interpretaciones.

b) Las organizaciones del Tercer Sector están sujetas a peticiones conflictivas procedentes de diversos grupos sociales, por ejemplo, los donantes-financiadores y los clientes-beneficiarios.

c) En buena medida, estas organizaciones confian en su network inter-personal con el fin de facilitar los flujos de recursos hacia y por parte de la organización.

Los estudios que han tenido como objetivo los dilemas de medición de la performance de las organizaciones del Tercer Sector también se han centrado en este aspecto de la multipleconstituency de estas organizaciones ${ }^{16}$. En dichos análisis, es el carácter central de los valores sociales respecto a los financieros el elemento que complica la medición en las organizaciones del Tercer Sector. En consecuencia, los test de buen funcionamiento deben ser diferentes en cuanto que no se definen en torno a la ganancia financiera, más bien estan vinculados a la mission y a los servicios que ofrecen. El hecho de tener una multiplicidad de sujetos sociales (constituency) potencialmente responsables (accountability) introduce una posterior complejidad. En función de esto, sólo reconociendo y teniendo presente la pluralidad y diversidad de fuerzas y sujetos que actúan interna, externamente -y relacionando ambas - en este tipo de organizaciones, es posibte 
definir niveles satisfactorios respecto a los que valorar lo realizado.

Llegados a este punto, especialmente innovativas para el estudio de la organización operativa de los sujetos del Tercer Sector resultan las aportaciones teóricas procedentes de la sociología relacional ${ }^{17}$. A diferencia de los anteriores estudios, que procedían por analogía con otros sistemas (Estado o Mercado) o individuaban categorías exclusivamente extemas o internas al Tercer Sector, el paradigma relacional propone un nuevo sistema de observación: las relaciones internas y externas que desarrollan estos sujetos organizativos. El resultado es presentar a este nuevo tertium del social como el producto de la diferenciación societaria en condiciones de creciente complejidad, estando caracterizado por: una propia cultura (carácter relacional -reticular - de la identidad y de los intereses orientados bacia un mix entre Gemeinschaft $y$ Gesselschaft), una normatividad propia (el Tercer Sector crea y utiliza autónomas formas de intercambio social), una propia operatividad (expresa formas onganizativas propias), un rol societario propio (en la división del trabajo social, el Tercer Sector se especializa en la producción de nuevos bienes llamados relacionales).

Según estas premisas, los sujetos del Tercer Sector expresan formas organizativas propias y específicas. Propias en cuanto que las organizaciones del Tercer Sector están caracterizadas por el hecho de movilizar particulares recursos y combinarlos según peculiares modalidades. Específicas en cuanto que deben ser contextos en los que pueda realizar la propia mission. A este carácter propio y específico se añade un consejo anunciado en páginas anteriores: tomar como punto de referencia a las onganizaciones de los grupos secundarios, y no las empresas de mercado o los servicios príblicos ${ }^{18}$.

Para el estudio de las formas organizativas del Tercer Sector, la sociología relacional aconseja, como regla general, proceder valorando los parámetros de las relaciones internas, los de las relaciones externas y, donde se pueda, tratar de analizar las inter-relaciones entre relaciones externas y relaciones internas. No hemos de olvidar que la organización es, en este terreno, un problema de diseño, mantenimiento y variación de los límites entre interior y exterior. En función de ello, los parámetros que resultan más útiles y significativos para el análisis de las formas organizativas del Tercer Sector son:

A. En el interior: la estructura de las tareas y de los cargos, los tipos y grados de recompensas por roles desempeñados interna y externamente, la movilización de los recursos del ambiente interno, los procesos de decisión (previstos y de hecho realizados), las modalidades electivas de los cargos y de formación de la policy colectiva, la modalidad de rendir cuentas los propios miembros. A su vez, estos parámetros pueden ser valorados a la luz de diversos criterios, por ejemplo: el grado de participa- ción consentido por la modalidad de las decisiones (si decide el singular operador, si decide por todos conjuntamente, si son los órganos directivos los que establecen las decisiones, etc., ...), el grado de flexibilidad de la división del trabajo social y público.

B. Hacia el exterior: las modalidades de acceso y salida de los miembros, las modalidades de financiación y de adquisición de los recursos del exterior, las facilidades externas para el cumplimiento de los roles internos, las formas de reconocimiento solicitadas desde el punto de vista jurídico en las relaciones con el Estado y en la contratación con otras agencias públicas y privadas, las formas de dar cuenta de las propias acciones y de los resultados obtenidos a las instituciones y a los entes externos. También aquí los parámetros pueden ser valorados en función de diversos criterios, por ejemplo: la mayor o menor selectividad de los requisitos solicitados para ser miembro, la mayor o menor dependencia de ciertas instituciones (en general, aquellas que constituyen las mayores fuentes de financiación).

No es aventurado decir que el uso de estos parámetros, y de los criterios apuntados para su valoración, permite el análisis de la organización operativa de las organizaciones del Tercer Sector como realidad sui generis. Más concretamente, se evita el reduccionismo de aquellos planteamientos que aplican al Tercer Sector los esquemas de las empresas de mercado o los esquemas de las organizaciones burocráticas públicas.

En conjunto, la valoración de la organización operativa del Tercer Sector, cómo se estructura y funciona (valoración de la relación entre prestaciones y resultados), debe confiarse a criterios que en parte serán los mismos del sujeto del Tercer Sector $y$, en parte, procederán de otro observador.

Para terminar esta relación de estudios e investigaciones que han tratado de dar luz a las características de la organización operativa del Tercer Sector y sus organizaciones, me parece oportuno incorporar una breve reseña sobre aquellas aportaciones que han pretendido individuar los desafios que necesariamente deben ser afrontados por los managers de las organizaciones de Tercer Sector ${ }^{19}$. Éstos pueden quedar sintetizados en el siguiente cuadro.

La utilidad de este esquema reside en que permite la inmediata individuación de las características organizativas y de gestión propias de las organizaciones del Tercer Sector, independientemente de las que presentan las empresas de mercado o las agencias públicas. Si bien los primeros seis desafíos (o requisitos), que asumen una manifestación específica en las organizaciones del Tercer Sector, son comunes a las organizaciones que actúan en otros sectores, el segundo grupo (7 al 12) es típico, y en cierto modo exclusivo, de esta tipología organizativa. 


\section{Desafios que deben afrontar los managers de las organizaciones del Tercer Sector}

1. Uilización de recursos y predisposición de apoyos para el cambio.

2. Dirigir y motivar al personal.

3. Construcción de un apoyo exiemo y difusión del conocimiento de la propia organización.

4. Mejoras de las prestaciones de la propia organización.

5. Presión temporal.

6. Falta de un ambiente de trabajo estimulante y de apoyo.
7. Conflictos con el Consejo de Administración.

8. Problemas con los dientes/usuarios y con grupos externos.

9. Integración de peticiones divergentes.

10. Recursos limitados e inciertos.

11. Presencia de voluntarios.

12. Falta de conocimiento managerial y experiencia.
Como posteriormente veremos, sólo en las organizaciones del Tercer Sector la relación entre el manager y el Consejo de Administración asume un carácter paradójico ( $7 .^{\circ}$ desafío). En cuanto que no puede fundarse en una clara relación entre propietarios (accionistas) y dependientes (dirigentes), asumen una especial importancia los elementos ideológicos, de status, de clase, de pertenencia, que dan lugar a un equilibrio inestable.

Otra característica de las organizaciones del Tercer Sector es tener una multiplicidad de sujetos (constituency) que pueden hacer valer su posición en la evolución de la gestión de la organización ( $8 .^{\circ}$ desafío).

Al tener que rendir cuentas públicamente (publicness), este tipo de organizaciones debe operar bajo la presión continua de grupos externos. Estos últimos someten a un constante examen las decisiones políticas y, a veces, presentan sugerencias inconciliables ( $9 .^{\circ}$ desafío).

No existe ninguna duda en torno al hecho de que, si son comparadas con otro tipo de organizaciones, las modalidades operativas del Tercer Sector presentan una incerteza y limitación con respecto a los recursos económicos y financieros $\left(10{ }^{\circ}\right.$ desafio). La situación se agrava por tener que depender, de manera significativa, de las contribuciones de otros sujetos públicos (entes y administraciones locales) y privados (empresas y singulares ciudadanos), cuya fiabilidad y continuidad en el tiempo está fuera de la capacidad de control de la organización. Otro elemento diferenciador de las organizaciones del Tercer Sector es la presencia de un elevado número de personal voluntario. Se trata de un elemento ambivalente. Por un lado, puede constituir una ventaja competitiva respecto, por ejemplo, a las empresas de mercado, por otro, conlleva numerosos problemas de gestión. Por parte del manager, la presencia de voluntarios requiere un esfuerzo y una atención mayor que la que presenta el personal contratado, bien sea por su participación a tiempo parcial, bien sea por la necesidad de tener que reforzar continuamente sus motivaciones (11. ${ }^{\circ}$ desafio). Para terminar, los directivos de las organizaciones del Tercer Sector suelen poseer un nivel más bien bajo de conocimientos y de utilización de técnicas de gestión. Máxime si tomamos como medida comparativa sus colegas de las empresas de mercado. Sobre este particular resulta especialmente interesante indagar en las carreras profesionales de las que proceden. Generalmente suelen ser carreras específicas (médicos, asistentes sociales) con poca o ninguna experiencia en el mundo de la gestión (12. ${ }^{\circ}$ desafío).

Concluyendo, a partir de la literatura examinada emergen dos elementos que, en mi opinión, determinan el carácter específico de las organizaciones del Tercer Sector:

1. La ausencia de una unidad de medida general, comparable al resultado económico en las empresas con fines de lucro.

\section{El estar gobernadas desde (directa, centradas en) la mission.}

Estos dos elementos sugieren la necesidad de tener presentes una serie de indicaciones a la hora de estudiar la organización operativa de las organizaciones del Tercer Sector. Dichas indicaciones pueden resumirse asi: resulta muy arriesgado utilizar los esquemas de las empresas de mercado o de las burocracias públicas para acercarse al estudio de las organizaciones del Tercer Sector y, con posterioridad, proceder mediante deducciones comparativas. El análisis de la organización operativa de las organizaciones del Tercer Sector tendrá mayores posibilidades de éxito si se toma como punto de referencia las organizaciones de los grupos secundarios. Junto a ello, la valoración de la relación entre prestaciones y resultados deberá confiarse a criterios que, en parte, serán aquéllos procedentes del sujeto de Tercer Sector y, en parte, los procedentes de otro observador. Ahora bien, siempre teniendo presente que la optimización organizativa no significa ser más rentable o hacerse cargo de ejecutar más normas legislativas. La optimización organizativa deberá encontrar un punto de equilibrio dinámico, procesual, entre resultados y recursos humanos a la luz de un continuum informal-formal. No se debe olvidar en ningún momento que la organización implica dilemas culturales y estructurales. 


\section{El management de las Organizaciones del Tercer Sector: principales ámbitos de intervención}

El desarrollo y consolidación de una solidaridad organizada debe medirse con el desafio de la eficiencia, o bien con el empeno por dotarse de una estructura interna adecuada ${ }^{20}$. Las investigaciones internacionales confirman que el tipo y la calidad de la dirección constituyen uno de los factores más críticos que influye de manera decisiva en los resultados de las organizaciones del Tercer Sector. Esta importancia de la calidad de la leadership viene acrecentada por el hecho de tratarse de organizaciones complejas que combinan tres elementos: una gestión administrativa, una asociación voluntaria de personas y relaciones personales de tipo informal ${ }^{21}$. A ello hay que unir dos lineas paralelas de autoridad: a) del consejo de administración al personal operativo, b) de los profesionales a los voluntarios ${ }^{22}$.

En las siguientes categorías pueden agruparse los principales asuntos tratados y discutidos en la literatura del sector ${ }^{23}$ :

1. El gobierno de la organización. Aquí vienen sometidos a examen los mecanismos a través de los que las organizaciones del Tercer Sector ponen a punto sus objetivos de largo período, a la par que conservan la integridad de la organización (se analizan las actividades del consejo de administración o comité de gestión).

2. Leadership ejecutiva. En esta categoría se agrupan los estudios sobre la modalidad y los instrumentos que los directivos de estas organizaciones consideran operativos para el desarrollo de las políticas y las orientaciones generales (las figuras clave son: el manager, el director, los cuadros intermedios y todos aquellos que tienen responsabilidades en la gestión de la organización).

3. Gestión de los recursos financieros. El problema de la disponibilidad económico-financiera que caracteriza a estas organizaciones, unido al carácter peculiar de sus fuentes de financiación, obliga al desarrollo de técnicas de gestión y de recogida de fondos muy específicas (la a-tipicidad y, al mismo tiempo, la peculiaridad de las medidas a emplear deriva de la necesidad de encontrar un equilibrio entre las entradas; éstas presentan exigencias de gestión no siempre conciliables: financiación pública, donaciones y contribuciones privadas, cuotas asociativas, ingresos procedentes de la venta de servicios, ...).
4. Gestión de los recursos bumanos. En función de las características estructurales de estas organizaciones, que las configuran como organizaciones de alta intensidad del trabajo (respecto al capital), la gestión del personal resulta ser uno de los aspectos cruciales de la administración (bajo esta categoría se incluyen las técnicas encaminadas a la gestión del personal contratado, del personal voluntario y de los colaboradores externos).

5. Gestión estratégica del cambio. Una considerable serie de presiones externas influyen de manera decisiva en las organizaciones del Tercer Sector. En buena medida, esto se encuentra ligado a las características institucionales y funcionales del ambiente organizativo en que actúan. En concreto, las organizaciones del Tercer Sector se encuentran subordinadas a los cambios del contexto legaladministrativo, a las mutaciones del clima político-social, a los desafíos derivados del cambio social, a las innovaciones procedentes del campo metodológico y profesional (una característica común de las organizaciones del Tercer Sector viene dada por el hecho de privilegiar estrategias de colaboración antes que estrategias competitivas a la hora de afrontar la mutación organizativa).

El resto de apartados de estas páginas estarán dedicados a profundizar en cada uno de los ámbitos mencionados, haciendo especial hincapié en la elaboraciones teóricas y empíricas recientemente producidas por los estudiosos de las ciencias manageriales. El fin no es otro que poner a disposición del lector un patrimonio cognoscitivo que, estando aún en formación, se encuentra avalado por un discreto nivel de formalización y sistematización.

\subsection{El gobierno de la organización}

Una de las mayores diferencias entre las organizaciones del Tercer Sector y las empresas de mercado viene dada por el rol desempeñado por el órgano al que corresponde el gobiemo de la organización (consejo de administración, comité de gestión, consejo de dirección, comité ejecutivo, etc., ...) ${ }^{24}$.

la acción del consejo de una organización del Tercer Sector puede ser representada a través de la persecución de una doble función:

a) La función externa, referente a las relaciones que dicho consejo mantiene con el ambiente de la organización.

b) La función interna, esto es, las relaciones entre el consejo y los sectores internos a la organización.

Dicho de otra manera, la función externa engloba el conjunto de medidas encaminadas a establecer la legitimación de la organización en la comunidad y a reforzar su poder relativo. 
Aquí se ubican todas aquellas medidas que tienen como fin atraer los recursos económicos. Por su parte, la función interna se expresa en las actividades de gobierno y de control del personal ${ }^{25}$.

Para saber el grado de integración-aislamiento de una organización del Tercer Sector con el ambiente exterior, un indicador muy utilizado y significativo es el que viene dado por el análisis de la composición del Consejo de Aministración o Comité de Gestión. Tal composición puede variar en función de la diversidad de las organizaciones externas representadas o en relación al grupo social de pertenencia de los miembros. Frecuentemente, la relación con el ambiente exterior es descrita en términos de mutua-cooptación. Ello significa que, por una parte, las organizaciones del Tercer Sector tienden a seleccionar los miembros de los propios órganos directivos entre los exponentes de las élites políticas, sociales y económicas de la comunidad/territorio de referencia; éstas presentan connotaciones homogéneas respecto a los valores y a la finalidad de la propia organización. Por otra, dichas élites utilizan los órganos de dirección para intercambiar informaciones, establecer acuerdos, crear alianzas (reforzando de esta manera la cohesión del grupo), o bien como instrumento para mejorar la propia imagen social y la propia reputación en la comunidad ${ }^{26}$.

Por lo que respecta a las dinámicas internas de las organizaciones del Tercer Sector, el rol del consejo presenta un especial interés en lo referente a la relación entre órganos de dirección y directivos. Ésta puede ser descrita como una interacción dinámica, lo que significa estar en situación de afrontar la tensión, siempre presente, entre ambos polos para alcanzar la construcción de un pacto de confianza (partnership). Frecuentemente, el eventual equilibrio alcanzado suele ser temporal y mutable debido a la presencia de factores estructurales que lo someten continuamente a discusión. Entre éstos cabe destacar:

1. La subordinación, desde el punto de vista formal, del management al Consejo de Administración (éste puede contratar, despedir y controlar a los directivos).

2. El que el Consejo de Administración sea el responsable último para la indicación de las líneas políticas generales de la organización.

3. El hecho de que el management sea frecuentemente el depositario de importantes informaciones (cruciales) que determinan las elecciones a asumir en los procesos de decisión.

4. El que los directivos, mediante la implementación de las políticas, puedan de hecho convertirse en la autoridad funcional de la organización ${ }^{27}$.

En el ciclo de vida de una organización del Tercer Sector, una serie de aspectos organizativos pueden romper el equilibrio entre las dos instancias (de gobiemo y gestión) a favor de una u otra parte. Por ejemplo, las diferencias de status socio-económicos de los miembros de los dos grupos influyen en la posible dominación de los órganos de gobiemo sobre los de gestión. Por otra parte, el reconocimiento externo del grupo profesional al que pertenecen los directivos puede favorecer la prevalencia de estos últimos sobre el Consejo de Administración. Otros factores de interés que pueden influir en beneficio de alguna de las partes son los referentes al control de la información y del conocimiento técnico necesario para el desarrollo de las actividades de la organización. Tampoco hemos de olvidar la presencia de relaciones sociales informales entre los miembros de los dos grupos y/o entre éstos y otros sujetos sociales. En breve, diferencias o semejanzas de planteamientos ideológicos o modelos ideal-típicos pueden incidir en la percepción de hechos importantes para la organización, acercando o alejando el consejo a la dirección. Conviene recordar que los objetivos cruciales cambian de importancia en el curso de vida de una organización del Tercer Sector y, concretamente, el poder puede pasar de un grupo a otro. Una reciente investigación, que recoge el estudio histórico-organizativo de veinte organizaciones italianas ${ }^{28}$, ha puesto de manifiesto cómo la profesionalización de los servicios prestados ha conllevado, de forma paralela, un aumento del poder de los managers en detrimento de los Consejos de Administración. Las conclusiones de dicho estudio no tienen un carácter general -se trata de organizaciones muy peculiares, de larga tradición histórica, vinculadas a la Iglesia católica - pero sirven para poner de manifiesto el carácter de interacción dinámica, calificativo que anteriormente he empleado para denominar el tipo de relaciones que se establecen entre el consejo y los managers.

En síntesis, a partir de la literatura especializada disponible, avalada por numerosas investigaciones empíricas, se puede afirmar que la relación entre el consejo y el management de una organización del Tercer Sector tiene un carácter ambivalente y el equilibrio de poderes, referente a cada una de las instancias, cambia según: las caracteristicas de la composición del consejo, los factores organizativos, las relaciones informales y las situaciones específicas (es decir, los eventos críticos de la vida de la organización).

Algunas investigaciones han subrayado cómo, frecuentemente, la participación del consejo en las actividades concretas de estas organizaciones es más bien bajo. Dicho de otra manera, la norma es más bien aquella de un compromiso pasivo de los miembros, con elevados niveles de ausencia en las sesiones (absentismo) y de ratificación de lo existente más que de promoción y desarrollo de actividades innovativas ${ }^{29}$.

Numerosos son los factores que pueden incidir en la acentuación de este comportamiento o la marcha hacia una partici- 
pación más activa por parte del consejo. Entre otros cabe destacar:

- La estructura de las fuentes de financiación de la organización (mayor o menor presencia de donaciones, o de financiación pública, o de ingresos procedentes de la venta de servicios).

- El nivel de complejidad organizativa (dimensiones estructurales, técnicas y fiscales).

- El grado de profesionalización del personal (directivos, personal contratado y voluntarios).

- La figura del director ejecutivo.

Este conjunto de factores ubican en una situación inestable y mutable el rol y las funciones del Consejo que, teóricamente, deberían ser representadas y representables a partir del concepto de responsabilidad de confianza. Según este concepto, los miembros del consejo son responsables de la confianza acordada por los diversos sujetos que tienen intereses en el buen funcionamiento de la organización (donantes, beneficiarios, entes públicos, colectividad en general). El concepto establece que los miembros del consejo sean responsables de la realización de al menos tres funciones:

a. El mantenimiento del bienestar financiero de la organización.

b. La salvaguarda de la mission de la organización.

c. La promoción de la participación de los ciudadanos y el control sobre la producción de bienes de pública utili$\mathrm{dad}^{30}$.

\subsection{La gestión de la organización}

Durante mucho tiempo, el mundo de la solidaridad ha desarrollado una actitud marcada por la indiferencia hacia lo que podríamos denominar las lógicas empresariales. Insuficiencia es el calificativo que puede aplicarse a las organizaciones del Tercer Sector en relación a los procedimientos administrativos y de contabilidad. No es arriesgado afirmar que la aproximación ha sido el rasgo que ha caracterizado la gestión y la remuneración del factor trabajo. Hay quien llega incluso a afirmar que, hasta finales de los años setenta, los instrumentos propios de management organizativo eran casi desconocidos por las organizaciones del Tercer Sector ${ }^{31}$.

Una de las principales razones de esta situación se encuentra vinculada a la tradicional tendencia de los directivos de estas organizaciones a dar por descontada la bondad intrinseca de sus actividades. Su sola existencia es vista como un hecho positivo, como un indicador de "buen trabajo, dejando en un segundo plano la necesidad de alcanzar unos objetivos concretos.
Por otra parte, en cuanto que las organizaciones del Tercer Sector tienden a creer en su propio funcionamiento, el fracaso en el alcance de los objetivos establecidos no es considerado como una señal de debilidad de la organización, sino, más bien, como algo que pone de manifiesto la necesidad de reforzar los propios esfuerzos ${ }^{32}$. Algunos son los factores que acentúan esta situación:

\section{El becho de estar caracterizadas estas organizaciones por} una débil influencia de los clientes/usuarios (los destinatarios de los servicios) sobre las operaciones, máxime si se toma como referencia los clientes/usuarios de las empresas de mercado.

II. El estar sometidas a una presión competitiva muy débil o casi inexistente, actuando en mercados muy limitados. Factores de este tipo impiden a los destinatarios de los servicios enviar feedback referentes al grado de satisfacción de las prestaciones recibidas.

III. La presencia de objetivos conflictivos, elemento éste que interfiere en la adopción de modalidades de programación racional. La pluralidad de sujetos presente en las organizaciones del Tercer Sector conlleva una multiplicidad de objetivos. Por ejemplo, la mayor dependencia de contribuciones financieras (donaciones) no ligadas a la distribución de servicios hace que no exista un claro control del mercado y que la influencia de los clientes sea reducida, en cuanto que estos últimos no pueden ser la principal fuente de financiación de la organización.

IV. La tendencia de la organizaciones del Tercer Sector a trasladar la atención desde el output al input, es decir, desde los resultados producidos a las actividades encaminadas a la atracción de recursos. Y, en cuanto que los criterios de valoración de la performance válidos en un caso pueden variar significativamente de los válidos en otro, existe una tendencia a desligar los criterios de valoración desde la distribución de las prestaciones.

V. El rol central jugado por los grupos profesionales en el interior de las onganizaciones del Tercer Sector. Los stândards profesionales responden a lógicas propias que pueden no encajar con las de la organización. Por otra parte, tienden a crear una rigidez que interfiere con el desarrollo de nuevas respuestas a las mutables necesidades de los usuarios. El poder de los profesionales está reforzado en las organizaciones del Tercer Sector a causa de la proximidad de dos fenómenos:

- La ausencia de test directos del mercado acerca de la satisfacción del cliente (fenómeno ya mencionado); 
- la voluntad de los donantes, tendente a obligar a las organizaciones a repetir comportamientos pasados (planteamiento conservador).

Se puede concluir diciendo que, si se quiere pasar del planteamiento actual (abacer el bien a los otross) a un modo de operar más duro desde el punto de vista de la gestión (abacer bien mientras se bace el biem), es necesario que las organizaciones del Tercer Sector adopten modelos organizativos que se centren en la calidad de las prestaciones realizadas y en los niveles de la performance de sus diversos componentes.

Respecto a los objetivos y las funciones de los dirigentes de las organizaciones del Tercer Sector, se puede incluso llegar a hablar de: .las dos caras del management. ${ }^{33}$. Más concretamente, por un lado, el dirigente se encuentra realizando un rol empresarial (entrepreneurship) en cuanto iniciador de nuevos programas o a través del desarrollo de nuevos recursos; por otro, recae sobre él la responsabilidad de la gestión del personal (personnel management).

Por lo que respecta al primer aspecto, los dirigentes son responsables de la marcha de las relaciones que la organización posee con su ambiente social, económico y político. Ello comporta una atención cotidiana y constante con una pluralidad de sujetos, tales como los miembros del consejo, los entes e instituciones con quienes se establecen reglamentaciones, los clientes, los usuarios, los donantes, etc., ... En cuanto al segundo aspecto, es competencia del management estabilizar el clima interior y mantener el control de las operaciones internas de la organización. Esta función comprende las siguientes actividades:

- Distribución de recursos y toma de decisiones referentes a la propia fuerza de trabajo.

- Valoración de la performance de las diversas unidades.
- Gestión de la contratación, retribución, transferencia y despido del personal.

- Fijar la realización de los diversos planes y políticas.

- Gestionar las crisis internas.

La función empresarial establece las diversas modalidades a través de las que la organización atrae los recursos del ambiente a cambio de servicios elaborados; la gestión de personal trata de desarrollar y mantener incentivos que estimulen y motiven a los trabajadores a la consecución de la mission.

Como conclusión de este apartado dedicado al management de las organizaciones del Tercer Sector, por una parte, es mi intención poner a disposición del lector un instrumento de análisis organizativo elaborado directa y explícitamente para estas organizaciones; por otra, presentar una serie de puntos críticos que estas organizaciones deben afrontar para el desarrollo de un sentido empresariab, en los entes sin fines de lucro.

En cuanto al primer propósito, el instrumento de análisis que presento es fruto de un grupo de trabajo que actúa en el ámbito del Center for Voluntary Organization del London Scbool of Economics ${ }^{34}$. El proyecto, denominado Total Activities Analysis (TAA), tras un periodo de experimentación de diez años, se ha convertido en un instrumento "analítico-práctico para individuar los problemas de las organizaciones del Tercer Sector. A partir de él se ha elaborado un esquema para el análisis de la situación organizativa existente con vistas a determinar las oportunidades de cambio. Según sus autores, el modelo propuesto no tiene un carácter prescriptivo, su objetivo es más bien establecer un cuadro general para la descripción y comprensión de la organización y para afrontar cuestiones organizativas cruciales.

\section{Funciones de las organizaciones del Tercer Sector}

Funciones operativas clave

1. Abastecimiento de servicios.

2. Programación.

3. Análisis de la demanda.

4. Mantenimiento de buenas relaciones públicas.

5. Recogida de fondos

La TAA se fundamenta en la utilización de diez amplias categorías de funciones de las organizaciones del Tercer Sector, elaboradas con sucesivos ajustes en el curso de los años de experimentación. Ellas se dividen entre funciones operativas clave (esto es, indispensables para la supervivencia de la organización) y funciones de apoyo de las precedentes.
Funciones de apoyo

6. Operaciones financieras.

7. Adquisición y formación del personal.

8. Gestión y coordinación.

9. Adquisición y mantenimiento del material y de los instrumentos.

10. Trabajo adninistrativo y de secretaria.
La TAA prevé un recorrido en cinco etapas (tres fundamentales y dos intermedias). La primera consiste en la aplicación del esquema a diez funciones de la organización en examen. La finalidad no es otra que individuar cuáles están efectivamente desarrolladas y cuáles no y, eventualmente, si existen otras no previstas. La segunda etapa establece las modalidades a través 
de las que las funciones son concretamente divididas entre el consejo y la dirección (estructura de la división del trabajo interior). Una etapa intermedia consiste en explorar las implicaciones de la situación ordinaria para el actuar cotidiano de la organización. Para terminar, la tercera etapa prevé la discusión de la subdivisión necesaria (óptima) de funciones entre consejo y dirigentes, y la individuación de los posibles cambios.

La correcta aplicación de la TAA debería conducir a la elaboración de una modalidad de trabajo entre consejo y management basada en un planteamiento de tipo colaborativo más que competitivo.

Como anunciaba con anterioridad, mi segundo propósito era presentar aquellos puntos críticos que deben ser afrontados y resueltos para el desarrollo de un sentido empresarial en los entes sin fines de lucro. Dichos puntos críticos son los siguientes:

1. La introducción de fórmulas que faciliten la capitalización, es decir, la dotación de capitales propios y adecuados para las tareas previstas (este aspecto será tratado con mayor profundidad en el siguiente apartado).

2. La consecución de modelos organizativos más evolucionados con la introducción de sistemas racionales de gestión empresarial, pero, sobre todo, de nuevas y adecuadas $f i$ guras manageriales, sin caer en ningún momento en la adopción a-crítica de los modelos de gestión empresarial.

3. La individuación de nuevas y más eficaces modalidades de inserción del trabajo y del desarrollo profesional, superando la contradicción entre el carácter personalizado y envolvente de la actividad desarrollada y el matiz burocrático y apático de las prácticas de gestión del personal generalmente utilizadas ${ }^{35}$.

Estos tres desafíos pueden resumirse asi: la necesidad de encontrar una alianza, inédita en muchos aspectos basta el dia de boy, entre solidaridad y eficacia de la gestión.

A continuación paso a analizar en profundidad las cuestiones referentes a la gestión de los recursos económicos y de los recursos humanos en las organizaciones del Tercer Sector.

\section{A. La gestión de los recursos económico-financieros}

En función del recorrido hasta ahora realizado, no debe resultar extraño un hecho del todo evidente: las onganizaciones del Tercer Sector presentan una estructura de las fuentes de financiación del todo particular. Esta particularidad depende y está estrechamente ligada a las características estructurales, a la tipología de las actividades y a las funciones sociales que toda organización del Tercer Sector realiza. También en este aspecto, las diferencias con las empresas de mercado y con las agencias públicas son notables. Concretamente se manifiesta en la forma mixta que la composición de las entradas asume en las organizaciones del Tercer Sector, bien presentando elementos de tipo mercantil (ganancias procedentes de la venta de servicios) 0 bien de tipo estatal (financiación priblica).

Numerosas investigaciones empíricas han demostrado la extrecha correlación (positiva o negativa, directa o indirecta, en función de algunas variables organizativas y ambientales) entre la tipología de las fuentes de financiación y la configuración organizativa interna. Dicho de otra manera, toda fuente de financiación obliga (en mayor o menor medida, directa o indirectamente) a la organización a adoptar determinadas prácticas operativas y a desarrollar una estructura de roles y funciones adecuada. El fin no es otro que el utilizar de la manera más eficiente los recursos disponibles. Sobre este aspecto resulta especialmente interesante la tipología de derivación socio-económica elaborada por HANSMANN ${ }^{36}$. Ésta pone en estrecha relación la naturaleza de la financiación de una organización, el sujeto que la realiza y el sujeto-objeto destinatario. Tal taxonomía prevé la fórmula de la auto-financiación, de la financiación exclusivamente derivada de un tertium extraño a la organización y de la modalidad mixta que se basa en la combinación de las anteriores. Paralelamente viene valorada la posibilidad de coincidencia entre los que financian el servicio y los que se benefician, o bien si hay una neta distinción entre los financiadores y los beneficiarios.

Excluyendo las posibles ganancias derivadas de una oculta gestión financiera (que, a excepción de las fundaciones, representan un montante muy limitado de los recursos monetarios de estas organizaciones), las principales fuentes de financiación de las organizaciones del Tercer Sector pueden agruparse así:

a) entradas derivadas del sector público;

b) entradas procedentes de la venta de bienes y servicios;

c) entradas que tienen su origen en donaciones;

d) entradas derivadas de las cuotas asociativas.

La primera, la financiación pública, constituye una de las grandes entradas dominante en las organizaciones del Tercer Sector del Occidente industrializado (situándose generalmente por encima de la mitad de los recursos de estas organizaciones, y no descendiendo por debajo de $1 / 3$, también teniendo en cuenta las diferencias intersectoriales: sanidad, servicios sociales, arte, cultura, medio ambiente, etc., ...) ${ }^{37}$. Internamente, esta fuente de financiación se articula en dos secciones: financiación directa y financiación indirecta. En el ámbito de la primera modalidad (directa) encontramos los dos principales instrumentos de soporte y apoyo a disposición del sector público para promover y promocionar las organizaciones del Tercer 
Sector: el sistema de las contribuciones y de las subvenciones (grants) y el sistema de las convenciones (contracts). La segunda forma de financiación (indirecta) comprende:

1. El conjunto de medidas encaminadas a conferir un status de exención (total o parcial) a la actividad y al patrimonio de la organización.

2. La atribución de la posibilidad de deducir del propio ingreso imponible, por parte de aquellos que ofrecen las contribuciones económicas, todo o parte de la suma donada.

Cada una de las formas de financiación pública mencionadas obliga a las organizaciones del Tercer Sector al cumplimiento de una serie de condiciones, a veces muy rigurosas en términos de procedimientos administrativos a seguir, de stándard a respuestas, que inciden fuertemente en la gestión y en la financiación de estas organizaciones. Por ejemplo, pueden individuarse tres modalidades de relación entre las organizaciones del Tercer Sector y el ente público, tomando como punto de partida la forma de financiación, los servicios desarrollados y las repercusiones de estas dos variables en la estructura organizativa:

1. Relación de tipo institucional, presente en las organizaciones del Tercer Sector con larga tradición histórica y con sólida inserción en la comunidad local. Aquí la colaboración entre público/organización del Tercer Sector sigue una praxis codificada, generalmente normalizada por leyes precisas, representando las contribuciones económicas procedentes de los entes públicos una dimensión de la relación que tiene los matices de lo rutinario y lo esencial.

2. Relación de tipo contractual, típica de las organizaciones del Tercer Sector que desarrollan y prestan específicos servicios por mandato del ente público. Éstos son asignados mediante diversos trámites de confianza, estando limitados en el tiempo y, por tanto, existiendo la posibilidad de que sean revocables. Al ser una relación que se fundamenta en la financiación por servicio prestado, este hecho puede derivar en un crecimiento de la capacidad de gestión y de la mentalidad empresarial de la organización. Al mismo tiempo está presente el riesgo de la desaparición del compromiso de solidaridad y de la misma posibilidad de desarrollo del Tercer Sector.

3. Relación de tipo proyectiva, presente en aquellas organizaciones que construyen una relación orgánica con los servicios públicos, fundamentada en la confianza y en la cooperación recíproca. Las actividades tienden a integrarse y a especificarse, los operadores se habitúan a integrar y compartir metodologías y objetivos, manteniendo el respeto a las correspondientes competencias y res- ponsabilidades. Las iniciativas del Tercer Sector tienden a no ocupar áreas de pertenencia de los servicios públi$\cos$, y se dirigen hacia nuevas necesidades o hacia modalidades de intervención de carácter innovativo, ligándose con los servicios existentes. La dimensión de la negociación -en la que se engloba la aportación financieraasume características más estables que las de un simple contrato. Puede diferenciarse en el tiempo y contemplar, de manera más favorable, objetivos de valor social como la inserción de sujetos débiles, la formación del personal o la promoción de proyectos piloto ${ }^{38}$.

El segundo tipo de financiación (entradas procedentes de la venta de bienes y servicios) consiste en dos actividades diversas:

a) El eventual recargo monetario de los servicios distribuidos en la consecución del propio fin asociativo (estatutario).

b) Las entradas derivadas de la realización de actividades comerciales marginales (que deben tener o poseer un carácter secundario en la organización y, si se quieren beneficiar de las exenciones fiscales eventualmente previstas, deben ser completamente invertidas en la organización con el fin de mejorar la capacidad de consecución de los fines vigentes en los estatutos). La diferenciación de la cobertura del coste de los servicios distribuidos a los usuarios, a partir de criterios que tengan en cuenta la capacidad contributiva de los singulares benficiarios, se ha convertido en una práctica común en los sistemas de welfare avanzados, bien sea por parte de las agencias públicas, bien sea por parte de las privadas sin fines de lucro. Obviamente, la difusión de este esquema de financiación y el peso creciente que viene asumiendo en el paquete de recursos de las organizaciones del Tercer Sector, impone profundos cambios de carácter estructural y de gestión.

La cuestión de la participación de la organizaciones del Tercer Sector en actividades comerciales, a fin de garantizarse una base económica más sólida para financiar las propias actividades solidarias y de asistencia, reclama la atención sobre el delicado aspecto de la acompetencia desleal (unfair competition), muchas veces señalado por las empresas de mercado que actúan en el mismo campo de actividades. El argumento se apoya en el siguiente razonamiento: en cuanto que las organizaciones del Tercer Sector gozan de beneficios fiscales y condiciones privilegiadas de acceso al mercado de trabajo y a las financiaciones, estas condiciones les permiten producir bienes y servicios a precios muy bajos, ubicándose en una posición de competencia desleal en comparación con las empresas de mercado. Al no poder afrontar este tema de manera más detallada por razones de espacio, tan sólo llamar la atención sobre el hecho de que la venta de servicios y de actividades comerciales marginales colocan 
a las organizaciones del Tercer Sector ante desafíos estructurales y de management totalmente diferentes de aquellos derivados de la financiación pública.

El tercer tipo de financiación (entradas derivadas de donaciones) posiblemente constituye la fuente más característica de estas organizaciones, aquella que de manera más explícita las distingue de las empresas de mercado y de las agencias públicas. Conviene señalar que ha sido objeto de una fuerte e incisiva campaña ideológica que ha tenido como consecuencia sobrevalorar lo que verdaderamente es y constituye ${ }^{39}$. Los resultados de esta presión no han sido otros que la distorsión del real alcance y de la concreta contribución provista por esta fuente de las organizaciones del Tercer Sector. Al margen de que la consistencia monetaria es más bien modesta en todos los países occidentales (y sólo en EEUU constituye aproximadamente un $1 / 5$ de los recursos económicos de estas organizaciones, teniendo incluso presente las diferencias inter-sectoriales) ${ }^{40}$, en la mayor parte de las ocasiones es concebida por la opinión pública (incluidos los operadores y los miembros de estas organizaciones) como la verdadera, la legítima fuente de financiación del Tercer Sector.

Las contribuciones económicas englobadas en la categoría de donaciones pueden proceder de dos tipos de actores:

- Singulares individuos (ciudadanos contribuyentes y familias).

- Entes e instituciones (fundaciones, empresas comerciales, bancos, etc., ...).

Por lo que respecta a la diferenciación cuantitativa existente entre estos dos tipos de sujetos, las investigaciones empíricas y las indagaciones socio-económicas han invalidado una imagen que se ha venido consolidando a lo largo del tiempo: la percepción de que la cuota procedente de las donaciones tuviese su origen principalmente en entes, empresas e instituciones. Al contrario, existe el común acuerdo, apoyándose en los datos derivados de la investigación empírica, de que la mayoría de las contribuciones tienen su origen en un amplio radio de donaciones procedentes de millones de ciudadanos corrientes, en su mayor parte pertenecientes a clases medias y medio-bajas de la población ${ }^{41}$. Desde el punto de vista de la gestión, esta fuente de financiación requiere el establecimiento y el desarrollo de forma sistemática de las funciones de relaciones públicas y de marketing, así como la utilización de diversas técnicas de recogida de fondos (fund-raising).

El cuarto tipo de entradas financieras está constituido por las cuotas asociativas y las contribuciones procedentes de los miembros de la organización. Se trata de una forma tradicional de financiación que no requiere la utilización de técnicas y mecanismos de gestión particularmente sofisticados. Más bien se debe desarrollar una política de marketing interno, es decir, de atención a los propios miembros; éstos deben ser vistos y tratados como verdaderos y propios clientes de la organización ${ }^{42}$. La demostración de una capacidad de escucha (atención a las sugerencias procedentes de los socios), de voluntad para poner en práctica las acciones prometidas, además de la adopción de una modalidad de gestión participativa, son elementos que refuerzan el clima motivacional de la organización y, con ello, el sentido de pertenencia de los singulares miembros ${ }^{43}$. Por último, conviene apuntar que, si se excluyen aquellas organizaciones de reducidas dimensiones, esta fuente de financiación está asumiendo un rol cada día más marginal en el interior de las fuentes de financiación de las organizaciones del Tercer Sector. Su puesto está siendo ocupado por las entradas derivadas de la venta de servicios a los usuarios y de los ingresos procedentes de la utilización de técnicas de recogida de fondos siempre más sofisticadas.

La cuestión de la gestión de las fuentes de financiación de las organizaciones del Tercer Sector merecería un trato más amplio del que aquí se ofrece. Por otra parte, por razones de espacio y de finalidad de estas páginas no es posible más que analizar brevemente tres aspectos que están asumiendo una importancia crucial en relación a las estrategias organizativas que estas organizaciones deben afrontar a fin de asegurarse una estable base económico-financiera. Se trata de fenómenos y prácticas tales como: la marketization, el contracting out y el fundraising.

Con el término marketization (comercialización) se entiende el proceso en virtud del cual las entradas procedentes de una venta directa de servicios a los usuarios van adquiriendo un peso cada vez mayor en la composición de la estructura de las fuentes de financiación de las organizaciones del Tercer Sector. Según esta interpretación, estas organizaciones caminan progresivamente hacia la confiada comercialización de los bienes y servicios elaborados, con el riesgo de asumir configuraciones organizativas muy similares a las de las empresas de mercado. Los resultados de diversas investigaciones empíricas vienen citados como apoyo de esta tendencia que, en los países anglosajones, parece estar adquiriendo amplias proporciones ${ }^{44}$. Desde el paradigma relacional, esta tendencia es interpretada como una mutación de las redes de las organizaciones del Tercer Sector, que más que activar el sentido de la intecambiabilidad social, privilegian la maximización de la eficiencia. En breve, esto supondría encontrarnos ante algo que no es el Tercer Sector, algo que es diferente ${ }^{45}$.

El proceso de marketization está especialmente presente en aquellas organizaciones que trabajan en los sectores de welfare, en buena medida como consecuencia de las más recientes reformas en el ámbito de las políticas sociales y sanitarias. Algunos expertos hablan de la emergencia de un cuasi-mercado ${ }^{46}$ para indicar la adopción de técnicas competitivas en el interior 
de los sistemas sanitarios nacionales, tradicionalmente caracterizados por una situación de monopolio. El fenómeno no es que sea de por sí enteramente negativo, ni totalmente positivo: $e l$ éxito en un sentido o en otro depende de las concretas modalidades puestas en acto por los actores participantes. Por una parte, esto debería traer consigo efectos positivos ligados a una mayor capacidad de respuesta por parte de las organizaciones a las peticiones de los usuarios que, insatisfechos por la calidad de los servicios, podrían, de forma teórica, dirigirse a otra agencia. En relación a este aspecto, nos encontramos con el aumento de las posibilidades de elección a disposición del cliente/usuario, dada la pluralidad de sujetos que realizan el mismo servicio. Por otra parte, la superación de las condiciones de monopolio precedentes debería conducir a una reducción de los precios de las prestaciones ofrecidas $y$, por tanto, de forma progresiva, a un aumento de la capacidad de caring (número de personas atendidas).

Al mismo tiempo nos encontramos con el riesgo de que las organizaciones del Tercer Sector se dirijan hacia aquella parte de la clientela que se encuentra en mejores condiciones para sostener el coste de los servicios ofrecidos, excluyendo de las propias prestaciones a los que se encuentran en condiciones desfavorecidas (efecto de selección de la clientela). En breve, no resulta aventurado afirmar que: existe la posibilidad, si estas organizaciones continuan crecientemente confiando en este tipo de financiación, de olvido de aquellas caracteristicas de fondo que babian permitido adquirir el status de non-profit, con la consiguiente pérdida de los privilegios fiscales y administrativos, pero, sobre todo, desde el punto de vista de su imagen (reputación) social (en cuanto entes solidarios).

Con el término contracting-out se hace referencia a una práctica en uso -ampliamente difundida - en todos los sistemas de welfare avanzados, práctica que recientemente ha sufrido un proceso de aceleración. Se trata de la adquisición, para su posterior distribución, de servicios elaborados por las organizaciones del Tercer Sector por parte del ente público. Este último las contempla como un actor-productor privilegiado.

Los aspectos organizativos y de gestión derivados del contracting-out son numerosos e inciden profundamente en la configuración de estas organizaciones. Merece la pena apuntar algunos ejemplos. En primer lugar, está el efecto positivo de poder contar, por un período de tiempo concreto, con una entrada segura (efecto de estabilización) que permite el no tener que invertir una cantidad notable de energías (humanas y organizativas) en la búsqueda de recursos económicos. Esto ofrece a estas organizaciones la posibilidad de embarcarse en proyectos y políticas de amplio respiro, de medio-largo período y de no estar obligadas a la adopción de estrategias de snavegación a la vista. En segundo lugar están los costes administrativos vinculados al proceso de presentación de la oferta, de prepara- ción de un proyecto detallado que comprenda un presupuesto económico, de elaboración de la documentación periódicamente solicitada por el ente público para valorar el respeto y el cumplimiento de los standards cuantitativos y cualitativos fijados, etc., ... ${ }^{4}$.

Sin embargo, desde el punto de vista del management, el aspecto más importante ligado a la utilización de la financiación pública viene dado por la gestión del flujo de caja (cash-flow). Como se sabe, el sistema de pagos realizados por la administración pública se basa en un principio ex post, es decir, en cubrir los costes ya realizados mediante la presentación de facturas o de justificantes. Esto obliga a las organizaciones del Tercer Sector a tener que realizar fuertes desembolsos de caja, por ejemplo, anticipos de gastos (administrativos, del personal, para la adquisición del material) que sólo serán cubiertos en una fase sucesiva (de duración variable, como media de tres meses a dos años). Esta continua necesidad/carencia de capital circular conduce a estas organizaciones a la petición de créditos a mediolargo plazo, con notables costes financieros (intereses pasivos de los prestamos). Por tanto, la prudente gestión y administración del casb-flow se presenta como una de las principales tareas de los management de las organizaciones del Tercer Sector. No hemos de olvidar que en estas organizaciones una parte importante de las entradas procede de conciertos y convenciones con los entes públicos para la provisión de servicios (contracting-out) ${ }^{48}$.

Una vía de salida a este impasse viene dada por la adopción -por parte de grupos de organizaciones del Tercer Sector- de soluciones de consorcio. Éstas permiten una consolidación y reforzamiento de la capacidad de contratación de las organizaciones (y de su poder relativo), bien sea en relación con el sector público, encontrándose en situación de asumir la gestión global de ramos completos de servicios, bien sea en relación con las entidades bancarias, ofreciendo un capital social de amplia base que garantiza la apertura de préstamos (con el consiguiente aumento de la suma monetaria a la que se puede acceder y la reducción de los intereses).

El término fund-raising designa una amplia gama de técnicas y de prácticas de recogida de fondos dirigidas a específicos target de población. Se trata de una propia y verdadera práctica de marketing elaborada para la consecución de objetivos sociales. Todas las organizaciones del Tercer Sector ponen en marcha, dé manera más o menos consciente, planificada y estucturada, estrategias para atraer recursos monetarios de lo que viene a ser considerado un potencial de donantes. Las campañas de recogida de fondos presentan diversas modalidades de realización. Van desde la organización de actos lúdico-culturales con fines benéficos, a la recogida de dinero puerta a puerta o con mesas de inscripción por las calles; desde el envío de mensajes a un amplio público a través de los mass-me- 
dia (TV, radio, periódicos, boletines internos), a la elaboración de mensajes personalizados enviados por correo (direct-mailing); desde las campanas telefónicas, a la recogida de fondos en lugares de culto, etc.

Respecto a los imperativos que el uso de esta estrategia impone a la organización, desde el punto de vista de la gestión, conviene recordar que: si, por una parte, la oferta latente (donantes potenciales) excede siempre a la demanda (de las organizaciones), por otra, existen umbrales de saturación más allá de los cuales se pueden verificar fuertes efectos perversos. Dicho de otra manera, una pésima gestión y dirección de la campaña de recogida de fondos puede producir efectos negativos en términos de pérdida de confianza en la organización y de prestigio en la comunidad (revelándose en último término contraproducente). Algunos aspectos cruciales que deben ser respetados para garantizar la eficacia de las operaciones son:

1. Congruencia entre el mensaje emitido y la mission de la organización.

2. La concreta individuación del target de población al que enviar el mensaje.

3. Explicación clara de los valores en los que se inspira la organización.

4. Demostración de un correcto empleo de los fondos recogidos.

5. La participación y la formación del personal encargado.

6. La construcción de amplias y estables relaciones con las personas/organizaciones clave de la comunidad ${ }^{49}$.

Una cuestión muy debatida en la literatura especializada es la relación que debe existir entre las sumas de dinero recogidas y los gastos invertidos para obtenerlas. Aunque en la actualidad no existe un acuerdo entre los expertos en torno a la individuación de la óptima relación, conviene señalar la presencia de una interesante convergencia de opiniones acerca de los gastos administrativos y de gestión. Éstos no deben superar el 30\% $(1 / 3)$ de la suma recogida si se quiere garantizar la eficacia de la función de fund-raising ${ }^{50}$.

Como conclusión de esta sintética panorámica de las principales fuentes de financiación de las organizaciones del Tercer Sector, emerge con fuerza una constatación evidente: a tenor de la pluralidad y variedad de tipologias onganizativas existentes, no es posible individuar un perfil bomogéneo y unitario, un modelo ideal-típico que pueda aplicarse de forma indistinta. Más bien al contrario, estamos frente a diferentes configuraciones (equilibrios siempre inestables) de los recursos económicos según la incidencia de diversas variables tales como: las formas organizativas (fundaciones, asociaciones, cooperativas sociales, organizaciones de voluntariado, grupos micro-comunitarios, etc., ...); los sectores de intervención (sanidad, servicios sociales, cultura, arte, medio ambiente, educación, etc., ...); las dimensiones y la edad de las organizaciones (pequeñas, medias, grandes; jóvenes, menos jóvenes, bistóricas, etc., ...); y de otras variables bien presentes en la teoria de las organizaciones (tecnologia, producto/servicio elaborado, ambiente socio-económico y politico, etc, ...).

\section{B. Lagestión de los recursos bumanos}

No es arriesgado decir que la gestión de los recursos humanos constituye uno de los aspectos cruciales y una de las tareas principales del management de las organizaciones del Tercer Sector. Más concretamente, las organizaciones que proveen servicios ( $y$ las del Tercer Sector están entre éstas) tienden a ser organizaciones de alta intensidad del trabajo que requieren una determinada fracción de capital para toda unidad de output ${ }^{31}$.

Estas características vienen a dar una mayor complejidad a las funciones de gestión del personal en la organizaciones del Tercer Sector, expresándose en dos direcciones principales:

1. Competir por la adquisición del personal en el mercado de trabajo (también voluntario).

2. Motivar al personal a través de la utilización de incentivos ad hoc.

Algunos son los factores de estas organizaciones que pueden favorecer o desfavorecer, respecto a las empresas de mercado, a la hora de atraer al personal cualificado:

a) Una atención y un compromiso constante en la calidad.

b) La imagen de la organización en cuanto institución caritativa y agencia distribuidora de bienes de utilidad pública.

c) Particulares limitaciones de los recursos disponibles.

d) La capacidad de proveer beneficios no pecuniarios compensatorios en lugar de recompensas financieras.

En concreto, conviene subrayar cómo el ambiente de trabajo que ofrece una organización del Tercer Sector presenta características interesantes y originales. Éstas pueden inducir a cierto tipo de personas a preferirlas en lugar de las empresas de mercado. Entre otras, habría que destacar: un clima más relajado, ritmos menos intensos, un control menos directo, una atmósfera de atención y sensibilidad por las personas y la presencia de estrategias de decisión colegiadas.

Por otra parte, una serie de elementos impiden y obstaculizan el uso de recompensas monetarias basadas en la performance con el fin de motivar al personal de las organizaciones del Tercer Sector. Sirvan de ejemplos la fuerte acentuación en el voluntarismo, las expectativas externas de compontamientos $y$ 
planteamientos altruistas, la relación del personal a partir de las motivaciones, el especial carácter estatutario de las onganizaciones del Tercer Sector, la falta de un criterio de valoración último, la fuerte presencia de grupos profesionales. Cada uno de estos aspectos confirma la debilidad de gestión de estas organizaciones, debilidad que se manifiesta en la ausencia de sistemas de gestión (bancos de datos, estadísticas, ...), en la reticencia a dar juicios diferentes sobre subordinados y en la falta de criterios y métodos de distribución de las retribuciones a partir de los méritos ${ }^{52}$.

Los diversos especialistas en la materia ${ }^{33}$ dividen los recursos humanos de las organizaciones del Tercer Sector en dos grupos diferentes con necesidades muy diversas $y$, a veces, opuestas:

\section{A. Personal retribuido.}

\section{B. Los voluntarios ${ }^{54}$.}

Respecto al personal retribuido, los puntos cruciales son el momento de la contratación (selección) y el establecimiento de un sistema de incentivos, pecuniarios o no, coherente con la mission de la organización. Ciertamente, una estrategia de adquisición de recursos profesionales dificilmente puede prescindir de incentivos motivacionales, pero, a la vez, tendrá que articularse en recorridos diversos:

1. La adquisición externa de personal ya formado, empleándolo a tiempo completo con retribuciones no muy diferentes de los niveles medios del mercado.

2. El empleo de ex-directivos que, con las actuales reestructuraciones empresariales, puede utilizarse con mayor frecuencia que en el pasado.

3. La preparación interna, con adecuados itinerarios de formación y desarrollo para el personal directivo, centrándose en personas jóvenes dotadas de buenos niveles de instrucción.

La no existencia de recursos económicos anula en la mayor parte de las ocasiones la primera posibilidad, pero ello no quita que pueda contemplarse como potencial, como objetivo hacia el que dirigirse. El segundo recorrido empieza a ser puesto en práctica y ofrece interesantes perspectivas, pero hay que tener presentes los problemas de compatibilidad biográfica y cultural: no parece fácil encontrar, entre las personas habituadas a ejercer roles de responsabilidad en empresas estructuradas, elementos que estén dispuestos a trabajar en organizaciones a menudo jóvenes, informales y poco jerarquizadas. Quizás presentan mayores posibilidades de realización las colaboraciones puntuales (consultas organizativas, contabilidad, obligaciones fiscales y similares), limitadas en el tiempo; o bien el empleo de ex-directivos que, durante su experiencia laboral en el mercado, han madurado una sensibilidad por el trabajo solidario y voluntario.

El camino más practicado es la tercera vía, presente en buena parte de las organizaciones del Tercer Sector. Ahora bien, es necesario equilibrar la formación on-the-job con iniciativas estructuradas de formación managerial "s.

Desde hace algunos años, la coyuntura de mercado de trabajo favorece el reclutamiento de jóvenes cualificados y dotados de un válido potencial de desarrollo. Sin embargo, el Tercer Sector aún parece débil e incierto en la elaboración de auténticas políticas de recursos humanos, políticas que comprendan la valoración profesional y las retribuciones a las personas capaces, además de motivarlas.

Al mismo tiempo, no se puede olvidar un importante riesgo: en una situación laboral dificil, a las organizaciones del Tercer Sector se acercan personas que, en realidad, buscan un puesto de trabajo y no están prioritariamente animadas por motivaciones solidarias. En consecuencia, la gestión del equilibrio entre cualificación profesional y valores de referencia aparece como uno de los nudos cruciales y críticos en torno al cual se construye el futuro de organismos: delicados y complejos como los entes del Tercer Sector.

En cuanto al personal voluntario, las fases más importantes son: el reclutamiento, la permanencia en la organización, la asignación a una tarea determinada, los aspectos motivacionales. Obviamente, las estrategias para el reclutamiento de voluntarios pueden basarse en una pluralidad compleja de motivaciones que van desde el interés personal (auto-estima, reputación, carrera, acrecentamiento personal) a motivos altruistas (bienestar de la comunidad, valores de solidaridad y caritativos, beneficios sociales). Un punto crucial es que los mensajes enviados no contengan imágenes o referencias contrarias u opuestas a la mission de la organización. De no ser así, la organización se encontraría con el problema de la presencia de sujetos voluntarios cuyas expectativas y referencias son totalmente diversas de las presentes en la propia organización del Tercer Sector ${ }^{\$ 6}$.

Dicho de otra manera, el elemento voluntario en las organizaciones del Tercer Sector presenta y puede presentar una amplia gama de situaciones. AmBrosin nos ofrece la siguiente taxonomía:

- Voluntarios marginales. Se relacionan con la organización de manera esporádica, ocasional o como ayuda a situaciones puntuales y contingentes. En consecuencia, tienen escasa importancia para el funcionamiento de la organización.

- Voluntarios ejecutivos. Asumen tareas simples y rutinarias de manera bastante definida. Esto permite liberar al personal profesional de ocupaciones que conllevan un 
consumo de tiempo sin tener una especial relevancia respecto a la calidad del servicio: por tanto, los operadores profesionales pueden dedicarse de manera más intensiva a otras actividades fundamentales y a las personas a las que la intervención está destinada.

- Voluntarios integrados. Mantienen una relación estable y continuada con la organización, a la par que desempeñan tareas significativas, pero éstas no revisten una importancia estratégica. Buenos ejemplos son la animación del tiempo libre, la organización de fiestas, momentos de encuentro, salidas. Por esta vía, indudablemente el voluntario contribuye a la personalización del servicio y a la humanización de la asistencia, especialmente en el campo de las actividades asistenciales. Las organizaciones del Tercer Sector pueden prever formas más o menos amplias de delegación de estas funciones al voluntario, concentrando los propios recursos en otras actividades. Pero, al mismo tiempo, puede inducir a riesgos de desmotivación del propio personal dependiente. Este último se encuentra ante la posibilidad de ser relegado a actividades menos gratificantes y ante una situación de latente conflictividad con los propios voluntarios.

- Voluntarios promocionales. Especialmente dedicados a tareas que vinculan a la organización con la sociedad local (relaciones externas). Por ejemplo, en este campo se engloban las actividades de búsqueda de financiación y de contribuciones privadas. También se incluyen aquí las funciones de representación y de divulgación de las actividades de la organización en congresos y en encuentros de diverso género. De forma mucho más amplia, en esta categoría se incluyen los compromisos comunicativos, dirigidos a hacer crecer el interés y el consenso hacia la actividad del ente, a aumentar la simpatía y la atención de la sociedad por el servicio ofertado. De igual manera, en sentido inverso, aportando a la organización informaciones y estímulos procedentes del exterior.

- Voluntarios profesionales. Se engloban aquí aquellas personas que desempeñan competencias específicas y cualificadas (médicos, psicólogos, educadores, asistentes sociales, etc., ...), y que ofrecen un servicio gratuito, no ocasional, para el desarrollo de las actividades de la organización.

- Voluntarios estructurales. Presentes en organizaciones cuyo núcleo operativo fijo está reducido al mínimo y las actividades se realizan en cuanto que existe un personal voluntario que se encarga de ellas. En este caso, las organizaciones del Tercer Sector no son entes que se apoyen en la aportación más o menos consistente de los voluntarios, más bien coinciden con el voluntario mismo, dotándose de un núcleo de coordinación con el fin de desempenar eficazmente la propia actividad.

Esta clasificación propone un tema poco investigado: a menudo se discute sobre la relación entre el elemento voluntario $y$ los servicios públicos, tendiendo a eludir la relación, vital y articulada, entre el elemento voluntario y las organizaciones del. Tercer Sećtor.

Tras este recorrido,-no resulta aventurado llegar a la siguiente conclusión: el ámbito de la gestión de las personas y de las relaciones inter-personales constituye el área que más claramente diferencia a las organizaciones del Tercer Sector de las empresas de mercado. Al fin y al cabo ipor qué trabajar en una organización del Tercer Sector si ésta no permite una clara visibilidad del propio trabajo? Generalmente, las organizaciones del Tercer Sector tienen que operar con una gran variedad de sujetos laborales, mucho mayor que la presente en las, organizaciones for profit o de mercado. Esto implica la siguiente necesidad: los directivos de las organizaciones del Tercer Sector deben utilizar las técnicas de gestión de los recursos bumanos.

I. En primer lugar, las personas requieren y tienen necesidad de que se les asignen tareas y competencias claras: si se alcanza este hipotético objetivo, las tradicionales formas de control se presentan obsoletas.

II. En segundo lugar, las organizaciones del Tercer Sector deben basarse en la información. Tienen que estructurarse en torno a flujos informativos que van desde los individuos que trabajan a los elementos directivos. Esta dimensión es esencial, las organizaciones del Tercer Sector tienen que ser organizaciones que aprenden.

III. En tercer lugar, el acento sobre la gestión de las personas debe concentrar la atención en la performance, sin minusvalorar los elementos de compasión que comporta el trabajo en las organizaciones del Tercer Sector. Por ejemplo, un frecuente problema en estas organizaciones viene dado por las personas que hacen voluntariado para superar situaciones de aislamiento y de stress. la organización debe ser capaz de integrarlas adecuadamente en la estructura y en la división de tareas y competencias organizativas, de lo contrario es preferible renunciar a este tipo de recurso.

IV. Por otra parte, los miembros de una organización del Tercer Sector (desde los directivos a los voluntarios) deben concentrarse en las tareas que les han sido asignadas. El siguiente paso es actuar de tal manera que las personas con quienes se trabaja las comprendan.

V. Por último, la organización del Tercer Sector debe ser una organización que sepa escuchar, pero que también sepa actuar en función de lo que ba sentido y aprendido. 
Una eficaz organización del trabajo facilita a las personas la realización de sus tareas, a la par que las hace agradables $^{\overline{ }}$.

\subsection{Planificación organizativa y gestión del cambio}

Para ubicar y afrontar el presente apartado es necesario dar respuesta al siguiente interrogante de amplias dimensiones: ¿Cuáles son las condiciones de crecimiento de las organizaciones del Tercer Sector valoradas positivamente en su significado . social, en sus funciones y en sus efectos?

Ante todo, senalar que una respuesta adecuada requiere la necesidad de distinguir entre lo que está fuera del control de los miembros de la organización, y lo que razonablemente puede depender de ellos. Se trata de un paso previo y necesario para analizar posteriormente los factores que, en uno u en otro caso, pueden favorecer o bien obstaculizar el crecimiento cualitativo-cuantitativo de las organizaciones del Tercer Sector:

A. Por una parte, están los factores sistémicos. Se engloban aquí aquellos factores que se sitúan fuera del control de las singulares personas, familias y redes informales. Se trata de factores que dependen de la dinámica macrosistémica de la sociedad en su conjunto y que trascienden, por así decir, al mundo vital. Estos factores pueden jugar a favor o en contra de la posibilidad de organizar los entes del Tercer Sector. Desde este aspecto, las sociedades complejas son profundamente ambivalentes: por un lado, necesitan de la comunidad del mundo vital, pero, por otro, están basadas en un orden social de individualismo institucionalizado que actúa contra ellas.

B. Por otra, están los factores del mundo vital que, en buena medida, dependen de los miembros de las organizaciones del Tercer Sector, o sea, están bajo su directo control. Que las organizaciones puedan ser construidas, promovidas, guiadas, favorecidas u orientadas en una dirección o en la otra, depende de los propios miembros que realizan sus específicas relaciones de lealtad y reciprocidad en el mundo vital.

Personalmente, creo que las condiciones de crecimiento del Tercer Sector y sus organizaciones se identifican con aquellos factores que aseguran la formación y el desarrollo del fenómeno asociativo a lo lango de sus propias distinciones-guia. Estas últimas no son otras que el ser iniciativas de personas que obran por el bien de la comunidad en la que viven, en nombre de una ética que se basa en el sentido de la confianza, de la reciprocidad, de la libertad en la responsabilidad, de la solidaridad, del compartir, de la equidad, del diálogo y del escuchar. A tenor de tales presupuestos:
1. Los factores sistémicos que obstaculizan, impiden o desvían el crecimiento de las organizaciones del Tercer Sector son todos aquellos que no ayudan a la familia a formarse y actuar como tal. Por ejemplo: una legislación o medidas de política social que adoptan una orientación de tipo individualista o colectivizante. Sin embargo, favorecen el crecimiento asociativo todos aquellos procesos y medidas que contemplan y favorecen el actuar solidario en las relaciones conyugales y entre las generaciones.

2. Igual acontece para los factores del mundo vital. Obstaculizan la formación y el desarrollo de las organizaciones del Tercer Sector todos aquellos factores que tienden a cerrar a los individuos, a las familias y a las redes informales en sí mismas, favoreciendo el privativismo, el narcisismo, la autarquía, la auto-referencialidad de los singulares. Por contra, los factores que ayudan a las organizaciones del Tercer Sector son todos aquellos que favorecen, aceleran y respetan el crecimiento de la autonomía de los individuos, de las familias y de las redes informales, orientándolas hacia el exterior, a la colaboración, a la capacidad de ver problemas comunes y de actuar conjuntamente para su solución.

Pienso que un grave error es pensar y contemplar las organizaciones del Tercer Sector sólo como el producto de factores extermos (ayudas de la sociedad, del Estado, el apoyo de los partidos políticos, etc., ...) o de factores internos (la generosidad personal, el sentido de apertura a los otros, la empatía intersubjetiva, etc., ...). Para evitarlo es necesario ver la correspondencia entre factores externos e internos, y saber instaurar un retículo virtuoso, no perverso, entre ellos. Dicho de otra manera, son importantes los reconocimientos y las ayudas externas (por ejemplo, una legislación que valore de la mejor manera posible las iniciativas de las organizaciones del Tercer Sector desde el punto de vista fiscal, administrativo, etc., ...) ${ }^{58}$. Ahora bien, también es necesario y esencial la conciencia del bien común en juego y la capacidad de promover una acción colectiva ${ }^{59}$.

Una vez establecido este marco de amplias perspectivas, pienso que estamos en condiciones de afrontar de forma más precisa la planificación organizativa y la gestión del cambio en las organizaciones del Tercer Sector.

Como punto de partida cabe señalar que las organizaciones del Tercer Sector son especialmente reticentes a adoptar estrategias de programación y planificación de medio-largo período en las prácticas organizativas. Algunos consicleran que este hecho se encuentra vinculado a la rigidez de los modelos de planificación utilizados en el sector público o en el mercado. Tanto uno como otro se basan en la idea de un desarrollo sucesivo por etapas según una lógica lineal ${ }^{60}$. Este planteamiento ha venido a menos en los últimos años. Los modelos de planifi- 
cación han reconocido el carácter no sucesivo de los procesos organizativos y la lógica intrínsecamente circular existente (equi-finalidad y multi-causalidad). En concreto, ha venido a menos la idea de que la planificación fuese reconducible a un único sistema unitario, aplicable a todos los contextos organizativos ${ }^{61}$. Actualmente se entiende por proceso de planificación la especificación de una secuencia de eventos o etapas de acción que mueven un sistema desde un estado presente a un estado deseado, consistente en el objetivo programático. El punto fundamental es que este planteamiento reconoce que la lógica de la secuencia de los eventos depende del contexto circundante y que, si el contexto cambia, igualmente debe cambiar la secuencia ${ }^{62}$.

La mayor parte de los estudios organizativos que han tenido como objeto específico las organizaciones del Tercer Sector revelan la menor capacidad de respuesta por parte de este tipo de organizaciones a los desafíos del ambiente, máxime si se toma como punto de referencia las empresas de mercado. En concreto, las organizaciones del Tercer Sector se presentan más impermeables a los cambios del ambiente circundante a causa de su particular ubicación en burbujas ambientales menos sensibles a las presiones de los mercados. Determinadas investigaciones sobre la difusión de los procesos de innovación, constatan como las organizaciones del Tercer Sector están caracterizadas por una rigidez organizativa que hace dificil el innovar o el cambiar. Por ejemplo, Moss y Summers, tras analizar una cadena de hospitales y residencias non profit estadounidenses, individúan tres elementos estructurales que afrontan y favorecen la innovación y tres factores críticos que la obstaculizan. Los primeros comprenden:

1. La asunción plena de la validez de la innovación por parte de los miembros más ancianos.

2. La presencia de una modalidad de trabajo de grupo de tipo colaborativo.

3. Una amplia gama de recursos externos a disposición del manager y de los operadores profesionales.

Los segundos, esto es, los factores críticos que obstaculizan la innovación son:

1. Varias formas de resistencia de los dirigentes y de los operadores clave, bien sean de naturaleza activa que pasiva.

2. Una difundida sensación de impotencia que caracteriza a los directivos de las organizaciones del Tercer Sector respecto a sus colegas de otros sectores.

3. La falta de sistemas de premios y reconocimientos, posible instrumento para estimular al personal a adoptar las innovaciones propuestas ${ }^{63}$.
En la misma línea de razonamiento se mueve J. Wolf. Tomando como punto de partida uno de los análisis más recientes sobre procesos de cambio en las organizaciones, Wolf ve en los entes del Tercer Sector la presencia de mayores problemas a la hora de emprender recorridos de cambio e innovación. Afirma que todo proceso de cambio organizativo comprende dos dimensiones: la tecno-estructural y la de las relaciones bumanas, debiendo proceder ambas de forma paralela y correlativa. Por otra parte, reconoce que el cambio organizativo es un proceso y no un evento, ello implica la adopción de una serie de pasos y etapas intermedias antes de que sea alcanzada la completa realización. La participación, según Wolf, es otro factor clave para determinar el éxito o no del proceso; esto es particularmente evidente en las organizaciones del Tercer Sector que, como he puesto de manifiesto en páginas anteriores, son organizaciones centradas sobre el factor humano.

Las características de base individuadas por Wolf como obstáculos a la adopción de innovaciones o cambios en las organizaciones del Tercer Sector son las siguientes:

a) Su naturaleza non profit (status-legal-juridico).

b) La amplitud y la indeterminación de la finalidad (objetivo estatuario).

c) Las características de las demandas puestas por el ambiente.

d) El mix de trabajadores contratados y voluntarios.

e) Su creciente estructura mixta (que comprende actividades de recogida de fondos, tareas comerciales, distribución de prestaciones y servicios).

Como conclusión, Wolf reconoce que el cambio y las innovaciones son inevitables $y$, en consecuencia, hay que ubicarse de manera que, si bien es difícil guiarlo de la forma deseada, al menos controlarlo para no debilitar (y eventualmente potenciar) la propia capacidad de alcance de la mission ${ }^{64}$.

No han faltado posiciones totalmente diferentes. Un buen ejemplo nos aparece en W. POWELL y R. FRIEDKIN. En cuanto a las posibilidades de cambio, ambos autores reconocen la existencia de notables diferencias entre las organizaciones del Tercer Sector y la empresas de mercado. Las segundas son tendencialmente más flexibles y plásticas. En buena medida ello está ligado a su fin último - generar beneficios para los accionistas-, que les permite una considerable libertad de elección en los medios para poder alcanzar tal objetivo. De forma teórica, una empresa de mercado puede cambiar sus productos retirar del mercado algunos servicios, comprar o vender otros; por su parte, la mission de una organización del Tercer Sector, bien sea de tipo solidario, educativo o cultural, establece mayores limitaciones a la flexibilidad de la acción. Abandonar la mission o cambiarla puede causar un serie de problemas legales y fiscales ${ }^{65}$. En síntesis, la 
principal diferencia entre las organizaciones del Tercer Sector y la empresas de mercado reside en la disparidad de acceso a los recursos y en los limites asociados a su adquisición.

Si ésta es la principal diferencia, las hipótesis que intentan verifcar POWEll y FrIEDKN, tomando como punto de partida el análisis de las principales teorías del cambio organizativo y la lectura de diez organizaciones que han sufrido procesos de cambio, son:

1. Que las organizaciones del Tercer Sector están sujetas a mayores presiones que las empresas de mercado, hecho éste que las induce a cambiar.

2. Que las organizaciones del Tercer Sector son capaces de responder a los cambios más que las empresas de mercado.

Tres son los factores individuados por estos autores para dar cuenta de este fenómeno:

a. La ausencia de una singular medida para valorar su performance. Esto está vinculado con el hecho de que los fines de las organizaciones del Tercer Sector son altamente politizables y no permiten fáciles y objetivas mediaciones.

b. La fuerte dependencia de recursos externos para su mantenimiento, hecho del que se deriva la vinculación a los cambios existentes en el clima político y económico.

c. La presencia de una pluralidad amplia de sostenedores y de usuarios de referencia (especialmente en las organizaciones del Tercer Sector de grandes dimensiones) que plantea demandas. De aquí se deriva una considerable flexibilidad organizativa.

Definiendo el cambio organizativo en las organizaciones del Tercer Sector como aquel proceso que implica una re-estructuración interna, pero que no comporta una transformación del objetivo (mission), POWELL y FrIEDKIN apuntan la existencia de tres posibilidades:

1. Quiebra por debilidad progresiva de la mission.

2. Fracaso como consecuencia de la pérdida de capacidad para el alcance de la missión.

3. Cambios adaptativos de éxito.

La primera posibilidad agrupa los casos de organizaciones del Tercer Sector en que los objetivos de la organización no se han alcanzado, pero la organización continúa existiendo. La segunda comprende la organizaciones del Tercer Sector que, a causa de presiones externas, han tenido que abandonar los objetivos iniciales y sustituirlos por objetivos alternativos a fin de mantener la supervivencia de la organización. La última posibilidad, cambios adaptativos de éxito, representa aquellos casos en que los objetivos originarios han sido alcanzados o se han reforzado por el cambio.
POWELL y FRIEDKINi concluyen afirmando que, del análisis de los casos estudiados, no es posible determinar con seguridad si las organizaciones del Tercer Sector están sujetas en mayor o menor medida a los cambios organizativos que las empresas de mercado. Por tanto, el cuadro que emerge es el siguiente:

- Encontrarnos ante organizaciones muy sensibles a las presiones ambientales.

- Estar ante actores organizativos sujetos a constantes procesos de adaptación creativa a fin de afrontar las peticiones procedentes de las componentes internas o de las relaciones externas.

En breve, a partir del análisis de la literatura disponible, los principales factores que potencian y favorecen el cambio organizativo en las organizaciones del Tercer Sector son los siguientes:

1. Una fuerte exposición a la influencia del sistema político y administrativo público.

2. Un débil control sobre las propias fuentes de financiación.

3. La complejidad técnica de gran parte de los servicios que se ofertan, realizan y distribuyen.

4. La dependencia de grupos profesionales que gozan de una fuerte cohexión interna a la par que de una gran reputación social.

5. El elevado grado de publicness, esto es, de responsabilidad pública. Esto conlleva el que sean organizaciones sujetas a las presiones de grupos sociales opuestos presentes en la comunidad.

6. El hecho de confiar, para la cobertura de las cargas más importantes de la organización, en las figuras de los líderes carismáticos más que en administradores competentes. En consecuencia, para las organizaciones del Tercer Sector el proceso de sustitución de los propios dirigentes resulta ser frecuentemente un problema. No constituyen una excepción las situaiciones de crisis que se resuelven con un nuevo diseño complejo de la organización (re-fundación).

\section{Razones y criterios de éxito para las organizaciones del Tercer Sector}

En este último apartado el objetivo es exponer los aspectos que pueden ser utilizados para definir el éxito de una organización del Tercer Sector. Con ello se pretende verificar si los crite- 
rios o las dimensiones de la vida organizativa individuadas, pueden ser trasladados a un cuadro de referencia unitario que permita elaborar una tabla de valoración de las prestaciones (performance) de las organizaciones del Tercer Sector. Para alcanzar tal meta me he basado en los criterios de éxito formulados como resultado del análisis de algunas organizaciones del Tercer Sector europeas.

Algunos estudios de caso hacen especial hincapié en el problema de la definición de los criterios con los que valorar y medir el éxito de estas organizaciones ${ }^{66}$. El razonamiento propuesto es el siguiente: después de baber examinado los métodos tradicionales de valoración del éxito en las empresas comerciales y baber demostrado que no son válidos y aplicables a las organizaciones del Tercer Sector, es necesario reconocer que estas organizaciones poseen características propias que determinan su originalidad y sus diferencias respecto a otros sujetos organizativos. Emerge entonces un interrogante: ¿Qué camino seguir para encontrar los criterios específicos aplicables a las organizaciones del Tercer Sector? La dirección no puede ser otra que las funciones distintivas de estas organizaciones, funciones que deben ser utilizadas como criterios respecto a los que valorar el éxito. Tales funciones son las siguientes:

a) Innovación, entendida en un doble sentido, bien como identificación y asunción de nuevas necesidades, bien como individuación de nuevas modalidades para afrontar las necesidades ya existentes.

b) Alternativa a la elaboración pública de servicios, entendida como medida encaminada a ampliar las oportunidades de elección por parte de los usuarios.

c) Ofrecer a los usuarios la oportunidad de contribuir a la definición y distribución del servicio (gestión participativa).

Al ser éstas las características/cualidades propias de las organizaciones del Tercer Sector, sólo teniéndolas como punto de referencia es posible individuar medidas con las que valorar el éxito o no de las organizaciones del Tercer Sector. Junto a estos criterios, referentes a los fines y a los objetivos de estas organizaciones (por tanto, miden la eficacia), también existe otro conjunto que engloba los medios activados para alcanzar tales objetivos (es decir, contemplando la eficiencia). Este grupo comprende los siguientes criterios:

1. La organización debe estar en situación de sobrevivir económica y políticamente.

2. La organización debe poder combinar la gestión de las actividades presentes con la búsqueda de recursos financieros futuros (concretamente, mantener el equilibrio, siempre inestable, entre financiación a largo plazo y financiación a breve término, constituye uno de los objetivos más difíciles en este tipo de organizaciones).

En función de estos criterios, las características estructurales y manageriales que justifican el éxito de una organización del Tercer Sector son las siguientes:

- Dar mayor poder (reforzamiento) a los productores de servicios (staff, voluntarios y operadores profesionales) y a los usuarios.

- Una estructura splanas y management participativo.

- Individuación de los límites con claros valores centrales y atribución a los trabajadores de responsabilidad y libertad dentro de este marco.

- Autonomía de las unidades locales.

- Especial atención a la formación y al desarrollo del staff.

- Una amplia gama de pequeñas actividades/proyectos separados pero relacionados entre ellos, y la disponibilidad para aprender de los otros (enseñanza recíproca).

- La innovación entendida como una cuestión de todos.

- Un fuerte núcleo central de staff pagado y una amplia periferia de trabajadores autónomos y voluntarios.

Estas características están presentes en la mayor parte de los programas de re-estructuración y re-organización de las empresas de mercado (conocidos bajo la denominación de cualidad total). Por tanto, aunque en un primer momento las organizaciones del Tercer Sector han cambiado las prácticas y los conceptos del management, nacidos en el ámbito del sector comercial, hoy, gracias a una aplicación original que ha sabido re-definirlos y mejorarlos, son estas organizaciones las que pueden aportar algo a las empresas de mercado.

Otros estudios han agrupado en cuatro puntos los elementos que definen el éxito de una organización del Tercer Sector ${ }^{67}$ :

1. El tener una solidez financiera.

2. Ser un centro reconocido dentro del ámbito en el que desarrolla sus actividades.

3. El clima organizativo interno.

4. Una buena capacidad de innovación.

Respecto al primer punto, éste consiste en saber perseguir con éxito una política de diferenciación de las propias fuentes de financiación y, en concreto, coordinar positivamente el sector de la captación de fondos y de la venta de servicios. Dicha coordinación tiene que derivar en $2 / 3$ de las entradas. La consecuencia directa será una fuerte autonomía respecto a las instituciones público-estatales. 
En segundo lugar, toda organización del Tercer Sector tiene que tener como objetivo el convertirse en un punto de referencia para la comunidad en la que se encuentra insertada. En breve, gozar del reconocimiento por parte de los organismos institucionales y de la sociedad civil.

El tercer punto centra su atención en la elevada participación por parte de todos los colaboradores 'de la organización en las instancias de decisión. En consecuencia, se puede afirmar. que el fin a perseguir es ser un verdadero modelo de co-gestión. Aún más, un hecho que debe poner de manifiesto el estar ante un contexto laboral acogedor y familiar, son los datos sobre la permanencia del personal (sea voluntario o dependiente). Debemos encontrarnos ante niveles muy bajos de rotación (turn-over).

Por último, el cuarto punto se refiere a las constantes actividades de verificación de las prestaciones elaboradas. La consecuencia que se debe derivar del tal hecho es el progresivo abandono de servicios que, con el paso del tiempo, no responden a las peticiones de la comunidad, y el desarrollo de actividades que estén más en sintonía con las necesidades de la sociedad actual.

Para terminar esta breve panorámica de criterios de éxito de las organizaciones del Tercer Sector, resulta especialmente interesante la individuación de afactores proclive realizada por algunas investigaciones ${ }^{68}$. Dichos factores pueden quedar sintetizados así:

- Los objetivos (entendidos en términos de usuarios a los que se dirigen, de metodologías y de proyectos realizados) deben insertarse perfectamente en una realidad percibida siempre de forma más clara.

- El personal debe tener y dar un importante sentido a su trabajo, de tal forma que se pueda hablar de un trabajo "casi militante.

- La organización del trabajo, que debe permitir amplios márgenes de maniobra a las diversas categorías de trabajadores, tiene que favorecer todo tipo de innovaciones (proyectivas, instrumentales y metodológicas).

- Establecer sólidos ligámenes con toda una serie de colaboradores institucionales, ligámenes que se fundamenten en la credibilidad y profesionalidad de las intervenciones realizadas por la organización del Tercer Sector.

- La organización debe saber desarrollar progresivamente los ainstrumentos de su políticas, gracias a una financiación que debe ser constante. Esto le permitirá correr riesgos y desarrollar más actividades.
Tras el ánalisis desarrollado a lo largo de estas páginas y teniendo presentes las aportaciones brevemente expuestas, emergen como puntos cualificantes y como dimensiones en tomo a las que construir indicadores para medir el éxito de las organizaciones del Tercer Sector, los siguientes elementos:

1. La capacidad de innovación y de experimentación.

2. El ser un instrumento para ampliar las oportunidades $\therefore$ electivas por parte de algunas capas de la población.

3. El ser un vehículo para la participación de los usuarios en el proceso decisional y en el control sobre la cantidad y la cualidad de los servicios.

4. La estructura de las fuentes de financiación.

5. El clima organizativo intemo y la modalidad de gestión de los voluntarios y del personal contratado.

6. La oferta de formación cualificada.

7. La relación de redes con otros sujetos del Tercer Sector y la capacidad de dar vida a nuevos organismos.

Los resultados procedentes de las anteriores investigaciones sirven de apoyo a la siguiente argumentación: no son las características intrinsecas (de carácter estructural) de las organizaciones del Tercer Sector las que bacen que esta tipología organizativa deba ser constitutivamente inferior a las empresas comerciales, en términos de capacidad de gestión y soluciones organizativas adoptadas. Más bien, las organizaciones del Tercer Sector se presentan como el lugar donde la sociedad experimenta soluciones innovativas que, posteriormente, son asumidas por las empresas de mercado y el ente puiblico. Al mismo tiempo, las organizaciones sin fines de lucro, voluntarias, solidarias, dan vida a un Tercer Sector en el que Estado y Mercado descargan muchas de sus disfunciones y costes externos. Por tanto, es necesario el desarollo de posteriores investigaciones comparativas internacionales (por ejemplo, a nivel europeo), inter-sectoriales (analizando trans-versalmente organizaciones que actúan en diversos sectores: sanidad, cultura, medio ambiente, derechos civiles, servicios sociales, etc., ...), bien sea a nivel micro (estudio del comportamiento de una o de un grupo limitado de organizaciones), bien sea a nivel macro (estudio de extensas network interorganizativas).

Sólo la difusión de una cultura managerial y de una práctica de valoración de las intervenciones podrá tener como resultado el bagaje de conocimientos necesario para el desarrollo de proyectos de programación y planificación a medio y largo plazo. Recuerdo "que este elemento constituye uno de los grandes vacíos de nuestro país respecto a otros contextos nacionales. 
- Universidad de Granada.

' Con el término Tercer Sector se entiende aquel conjunto de organizaciones que están caracterizadas por -una alta motivación altruista que induce a los sujetos a individuar necesidades colectivas no atendidas suficientemente por la accion del Mercado o el Estado, y a transferir recursos productivos (trabajo, capital o actividades empresariales) para contribuir a satisfacerlas (M. BASSANINI, P. RANCI, 1990: 18).

2 En el ámbito internacional, se ha difundido ampliamente aquel modelo que contempla al Tercer Sector desde las categorías público-privado. Personalmente creo que observar el Tercer Sector desde dichas categorias, significa estudiarlo y analizarlo desde la óptica del Estado o del Mercado. En consecuencia, se le define en negativo y por exclusión (es decir, como aquello que no es ni Estado, ni Mercado), olvidando los elementos distintivos internos del Tercer Sector, asi como lo que emerge de sus inter-acciones con el resto de sectores que componen el sistema societario (Estado, Mercado y Redes Primarias).

"Me refiero a la teoria de las poblaciones onganizativas o planteamiento ecológico de las organizaciones, nacida en la década de los setenta en EEUU de la mano de autores como M. Haninan y J. Freemain (1977), (1989).

${ }^{4}$ Buen ejemplo lo encontramos en EEUU, donde existe una interesante gama de cursos de cualificación, de master y de doctorados dedicados a los temas organizativos y de gestión propios de las organizaciones non profit. Entre las instituciones educativas más prestigiosas conviene destacar la Escuela de Fund-Raising del Center on Philantbropy de la Universidad de Indiana y los Master of Nonprofits Organizations del Mandel Center fon Nonprofit Organizations de la Case Western Reserve University (Cleveland) y del Institute for Policy Studies de la Jobns Hopkins University (Baltimore).

5 Véase A. ARDico (1981).

- Con el término bien relacional se alude a un bien que sólo puede ser producido y consumido conjuntamente por aquellos que son los mismos productores y usuarios a través de las relaciones que conectan a los sujetos participantes. El bien recibe el calificativo de relacional en cuanto que es (está en) relación. Según se trate de relaciones primarias o secundarias hablaremos de bienes relacionales primarios o bienes relacionales secundarios o colectivas. Sobre el concepto de bienes relacionales colectivos véanse: P. Dovat1 (1991:150-167), (1993: 118-128).

' Por observación exterma entiendo contemplar el Tercer Sector desde el punto de vista de los otros sistemas e instituciones que, en la sociedad, observan al Tercer Sector, dándole una propia definición. Mientras que observación interma significa ubicarse en el punto de vista del Tercer Sector, que mira a la sociedad, con sus sistemas e instituciones, y se autodefine por referencia a esta última.

${ }^{8}$ H. Hansmann (1981).

$\checkmark$ Véase I. Colozzi, A. BASSI (1995).

${ }^{10}$ Especialmente interesantes resultan las aportaciones de R.N. ANTHONY, D.W. YOUNG (1990).

"Fenómeno emergente, tal y como viene entendido en el planteamiento morfogenético. Véanse P. DONATI (1991), M. ARCHER (1995).

12 Véanse P.C. NuTt, R.W. BACKOFF (1992).

${ }^{13}$ Buen ejemplo son las aporaciones de T.H. JeAvons (1993).

14 Véanse R. PaGe (1991), C. Rancl (1990), (1992), J.T. Godbout (1993), L. Boccacin (1995).

15 Una interesante lectura de los conceptos töinnesianos desde la clave relacional puede encontrarse en P. Donam (1991: 87-92), (1996: 31-33).

${ }^{16}$ Véase R. Moss y D.V. Summers (1987).

17 Véase P. Dovın (1991), (1993), (1996).

${ }^{18}$ No estaría de más reclamar la clásica obra de COOLFY (1963).

${ }^{19}$ Entre otras cabe destacar la investigación llevada a cabo por C.D. MacCAurfY y M. HuGries (1993). Sus resultados proceden del estudio de trescientas organizaciones del Tercer Sector que actúan en el campo de los servicios socio-sanitarios del algunos Estados del Este de EEUU.

30 Véase M. Ambrosin (1994).

"Véase D. Buws (1990).
I Véase R. Kramer, B. Grossmann (1987).

". Vèase D. Yousg (1993), (1993a).

24 Para abreviar, uilizaré el término consejo para referirme a este órgano. Pero advierto que puede recibir diversas denominaciones.

${ }^{3}$ M. Middieton (1987).

${ }^{36}$ Véase I. Colozzl, A. Bass! (1995).

$\because$ Véase M. MiddLeton (1987).

Véase M. AMBRosN (1994).

9 J.R. SAIDEL (1993).

. J.R. SADEl (1993).

"Véase D. Young (1987).

32 Véase R. Moss y D.V. Summers (1987).

3 Esta fórmula ha sido acuñada por parte de D.R. Young (1987).

4 Véase M. HarrIS (1993).

35 Véase G. Rebora (1991).

.6 Véase H. Hansmavin (1989)

$"$ Véase L. Salamon (1993).

3 M. AMBROSIN (1994).

3) A. ARDIGO (1981).

4) Véase C. Badelt (1990).

"Véanse V. Cesareo, G. Rossi (1989), E. James (1990), L. Salamon, H. Aheier (1992), I. COLOZZJ, A. BASSI (1995).

12 L.W. KENNEDY (1991).

43. L. Boccacin (1995).

"Néase L. Salamon (1993).

45. P. DONAT (1996).

46 J. Le Gravd, W. Bartuett (1993).

"Véase S. Bernstein (1992).

* Véase K.A. Gronbjerg (1990).

4) M.A. DuRONIO, B.A. LOESSLN (1993).

5o Vénase R. Steinberg (1986), J. Wolf (1990), M. TAYlor, P. Hogcett (1993), Perri 6 (1994).

"R.N. ANTHONY, D.W. YOUNG (1990).

;2 Véase D.W. Young (1993).

5. Véanse T.H. Jeavons (1993), J.L. Brudney (1993), D.W. Young (1993).

* Respecto a este segundo grupo, Drucker plantea la necesidad de cambiar la consideración de estos trabajadores como voluntarios y pasar a considerarlos como personal no retribuido. Véase P.E. DRUCKER (1992).

"Véase A. ARDIco (1992).

36 Véase T.H. JeAvons (1993).

$"$ Véase P. DrUCKER (1992).

so Véase B. WEISBROD (1989).

* Véase P. Donat ( 1996).

6). T.H. JeAvons (1993); J. WOLCH (1990).

${ }^{61}$ Véanse G. Morgav (1989); P. Donat (1993); R. Siza (1994).

6? Véase I. ColozzI, A. BASsI (1995).

${ }^{63}$ Véase R. MOSS KANTER, D.V. SUMmers (1987).

${ }^{64} \mathrm{~J}$. WOLF (1990).

6s Véase W. PowEL, R. FrIEDKN (1987).

"o Véase, por ejemplo, el análisis que realiza D. LEAT sobre la Liverpool Personal Service Society (1994). 
$\sigma^{-}$Un buen ejemplo lo encontramos en el estudio realizado por L.T. TABLV (199j) sobre una organización del Tercer Seccor suiza, el Cenire Social Protestand-Vaud.
65 Véase A Alicuux (1995) y su estudio sobre la organización del Tercer Secaor belga llamada formation pour l'Université ouverte de Cbarleroi

\section{Bibliografia}

AMBrosin, M. (ed.) (1994), L'efficienza della solidarietà, Vita e Pensiero, Milán.

A.vCAuX, A. (1995), La FUNOC - Formation pour l'Université ouvente de Cbarleroi-, en A. Bassi (ed.) (1995).

ANHEER, H. y SEBBE, W. (eds.) (1990), The Tbird Sector. Comparative Studies of Nonprofit Organizations, DeGruyter Publications, Berlín-Nueva York.

AVTHONY, R.N. y YOUNG, D.W. (1990), Characteristics of Nonprofit Organizations, en Gies, Steven Or, Shafriz (eds.) (1990), pp. 216-34.

ARCHER, M. (1995), Realist Social Theory: The Morphogenetic Approach, Cambridge University Press, Cambridge.

ARDiGo, A. (1981), Voluntaritato, Welfare Siate e Terza Dimensione, en La Ricerca Sociale, n. 25.

_. (1992), Il woluntariato nel quadro del pluralismo associativo di solidarietà e la legge n. 266 91 , paper presentado al II Congreso Nacional sobre el Voluntariado, Asis, 14 16 de febrero.

BADELT, C. (1990), Institucional Choice and the Nonprofit Sector, en Anheier, Seibel (eds.) (1990)

Bassı, A. (ed.) (1995), Organizzazioni di successo, Angeli, Milán.

BASSAVINI, M.C. y RavCI, P. (1990), Non per profitto, Fundación A. Olivetti, Milán.

BERNSTEIN, S.R. (1991), Managing Contracted Services in the Nonprofit Agency, Yample Univesity Press, Filadelfia.

Buws, D. (1993), Organising Public and Voluntary Agencies, Routledge, Londres.

BocCACIN, L. (1995), Le associazioni di auto-aiuto in Italia, Fundación Italiana para el voluntariado, Roma.

BRUDNEY, J.L. (1993), Strengthening Volunteer Administration tbrougb Continuing Education and Research, en Young, Hollister, Hodgkinson y otros (eds.) (1993).

CESAREO, V. y RossI, G. (1989), L'azione voluntaria nel mezzogiomo, EDB, Bolonia.

Cotozzi, I. (eds.) (1994), .Terzo Settore e nuove politiche sociali in ltalia e in Europa., volumen monográfico de la revista La Ricerca Sociale, n. 49.

Colozzı, I. y BASSI, A. (1995), Una solidarietà efficiente, NIS, Roma.

COOLEY, C. (1963), L'organizzazione sociale, Comunita, Milán.

Donatn, P. (1991), Teoria relazionale della società, Angeli, Milán.

_ (1993), La cittadinanza societaria, Laterza, Roma-Bari.

_ (1996), Sociologia del Terzo Settore, NIS, Roma.

DruCKER, P.E. (1992), Managing the Nonprofit Organization. Principles and Practices, HarperBusiness, Nueva York.

DuRONI, M.A. y LOESSIN, B.A. (1993), Management Effectiveness in Fundraising, en Young, Hollister, Hodgkinson y otros (eds.) (1993).
GTES, D.L.; STEVEN Ot, J. y SHAFRTZ, J.M. (eds.) (1990), Tbe Nonprofit Organization. Essential Readings, Books/Cole Publishing Company, Pacific Grove.

GoDBOut, J.T. (1993), Lo spiritu del dono, Bollat Boringhieri, Turín.

GRONBJERG, K.A. (1990), Managing Nonprofit Funding Relations: Case Studies of Six Human Services Onganizations, POMPO Working paper, n. 156.

Havina, M.T. y Freemaiv, J. (1977), The Population Ecology of Organizations, en American Joumal of Sociology, n. 5, pp. 929-64.

Haviun, M.T. (1989), Organizational Ecology, Harvard University Press, Cambridge.

Havsmavis, H. (1981), Nonprofit Enterprise in the Performing Arts, en Bell jourmal of Economics, n. 12, pp. 3461

_ (1989), The Two Nonprofit Sectors: Fee for Services versus Donative Organizations, en Hodgkinson, Lyman (eds.) (1989).

HaRRL, M. (1993), Clarifying the Board Role: A total Activities Aproach, en Young, Hollister, Hodgkinson y otros (eds.) (1993).

Hodgknson, V.A. y LYMAN, R.W. (eds.) (1989), The Future of the Nonprofit Sector, Jossey-Bass Publishers, San Francisco.

JAMES, E. (1990), Economic Theories of the Nonprofit Sector: A Comparative Perspective, en Anheier, Seibel (eds.) (1990).

Jeavons, T.H. (1993), The Role of Values: Management in Religiosus Onganizations, en Young, Hollister, Hodgkinson y otros (eds.) (1993).

KENNEDY, L.W. (1991), Quality Management in the Nomprofit World, Jossey-Bass Publishers, San Francisco.

Kramer, R. y Grossman, B. (1987), -Contracting for Social Services: Contract Management and Resource Dependencies, en Social Services Review, n. 1, pp. 32-55.

LEAT, D. (1994), The Development of Community Care by the Independent Sector, Policy Studies Institute, Londres.

Le Grand, J. y BartzetT (eds.) (1993), Quasi-Markets and Social Policy, Macmillan, Londres.

MCCAUIFY, C.D. y HugHES, M.W. (1993), Leadership in Human Services: Key Challenges and Competencies, en Young, Hollister, Hodgkinson y otros (eds.) (1993).

MidDLETON, M. (1987), Nonprofit Board of Directors: Beyond the Governance Function, en Powell (ed.) (1987).

MORGan, G. (1989), Images: Le metafore dell'organizzazione, Angeli, Milán.

Moss Kaivter, R. y SUMmers, D.V. (1987), Doing Well While Doing Good: Dilemmas of Performance Measurement in Nonprofit Organizations and the Need for a MultipleConstituency Approach, en Powell (ed.) (1987).

NUTT, P.C. y BACKOFF, R.W. (1992), Strategic Management of Public and Third Sector Organizations, Jossey-Bass Publishers, San Francisco.

PAGE, R. (1991), Altriism and Social Policy, Avebury, Aldershot Hampshire. 
PERR, 6 (1994), Che cose e un'associazione? Definizione dei settori non-profit e dell'assaciazionismo, en Colozzi (eds.) (1994).

POWEL, W. (eds.) (1987), The Nonprofit Sector: A Research Handbook, Yale University Press, New Haven.

POWEL, W. y FrIEDKIN, R. (1987), Onganizational Change in Nonprofit Organizations, en Powell (ed.) (1987), pp. 180-94.

SAIDEL, J.R (1993), The Board Role in Relation to Government: Alternatives Models, en Young, Hollister, Hodgkinson y otros (eds.) (1993).

Salamo:y, L. (1993), The Global Associational Revolution: The Rise of The Third Sector on the World Scene, paper n. 15, The Johns Hopkins University, Institute for Policy Studies, Abril.

SAlAMON, L. Y ANHEIER, H. (1992), In Search of Nonprofit Sector I: The Question of Definition, working paper n. 2, Institute for Policy Studies, Baltimore.

SIzA, R. (1994), L'idea de società civile, Angeli, Milán.

STEINBERG, R. (1986), Nonprofit Organizations and the Market, en Powell (ed.) (1986).
Ravcl, C. (1990), Il mondo non profit, Fundación A. Olivetti, Milán.

REBORA, G. (1991), Democrazia pluralista e libertà associative, Giuffré, Milán.

TABIN, J.P. (1995), Le Centre Social Protestand-Vaud, en A. Bassi (ed.) (1995).

TAYIOR, M. y HOGGETT, P. (1993), Quasi-Markets and the Transformation of the Independent Sector, paper presentado a ta Conferencia Quasi-Markets: The Emerging Issues, Bristol.

WesBROD, B. (1989), The Complexities of Income Generation for Nomprofits, en Hodgkinson, Lyman, (eds.) (1989)

Wolch, J. (1990), The Shadow State, The Foundations Centre, Nueva York.

YounG, D.R (1987), Executive Leadership in Nonprofit Organizations, en Powell (ed.) (1987).

- (1993), Emerging Themes in Nonprofit Leadership and Management, en Young, Hollister, Hodgkinson y otros (eds.) (1993).

YounG, D.R.; Houster, R.M.; Hodgkinson, V.M. y otros (1993a), Governing, Leading and Managing Nonprofit Organizations, Jossey-Bass Publishers, San Francisco. 